\title{
On the Overturning Instability of a Rectangular Rigid Block Under Ground Excitation
}

\author{
Anthony N. Kounadis* \\ NTUA, Foundation for Biomedical Research of the Academy of Athens, Soranou Efessiou 4, Athens 11527 \\ Greece
}

\begin{abstract}
This paper deals with the rocking response of a free-standing rectangular rigid block subjected to a ground acceleration assuming that the friction between the block and the ground is large enough so that there is no sliding. Particular attention is focused on the minimum acceleration amplitude which may lead the block to overturning instability. The conditions of such a critical state are properly established. Subsequently, two distinct modes of overturning instability under a one-sine ground pulse are examined: (1) overturning without impact and (2) overturning after one impact occurring either before or after the ground excitation expires. The effect of initial conditions on the minimum amplitude acceleration is also discussed in connection with a one-cosine and a one-sine pulse. The proposed technique is applied to various examples covering all possible cases of overturning instability.
\end{abstract}

Keywords: Overturning instability, rigid block, impact, rocking motion, ground excitation, nonlinear and linearized analysis, and dynamic response.

\section{INTRODUCTION}

In recent years the attention of various researchers was focused on the rocking response of free-standing multi-drum columns carrying statues at their tip. A fundamental relative problem for the dynamic analysis of such a column-statue system is the rocking response of a free-standing rigid block for which various interesting studies have been presented lately [1-6]. This work is an extension of the last studies by presenting some new results via a simple and comprehensive analysis.

Consider a rectangular rigid block with dimensions $2 \mathrm{~b} x$ $2 \mathrm{~h}$ and total mass $\mathrm{m}$ which is in a vertical equilibrium position under its own weight (Fig. 1). The angle $\alpha=\tan ^{-1}(\mathrm{~b} / \mathrm{h})$ is the stockiness parameter (inverse of the slenderness ratio) of the block.

Depending on the form and magnitude of the ground excitation, the block may translate with the ground, slide, rock or slide-rock. Later work [1] on this subject showed that in addition to pure sliding and pure rocking a combined sliderock mode of rigid body motion may also occur. This depends not only on the ratio $\mathrm{b} / \mathrm{h}=\tan \alpha$ and the static friction coefficient $\mu$ - as was believed in the past - but also on the magnitude of the ground excitation. Subsequently, it is assumed that the coefficient of friction $\mu$ is large enough so that there is no sliding.

Under a positive horizontal ground excitation (displacement or acceleration) who's magnitude is sufficiently large [5] the rigid block will initially rotate with a negative rotation $\theta<0$ (Fig. 2a), and if the block does not overturn it will eventually assume a positive rotation, and so on. However,

*Address correspondence to this author at the NTUA, Foundation for Biomedical Research of the Academy of Athens, Soranou Efessiou 4, Athens 11527 Greece; Tel: +30-210-6597517; Fax: +30-210-6597517; E-mail: kounadis@bioacademy.gr as will be shown, if the positive excitation is moderate the rigid block will initially rotate with a positive rotation $\theta>0$ (Fig. 2b), and if it does not overturn it will eventually assume a negative rotation, and so on.

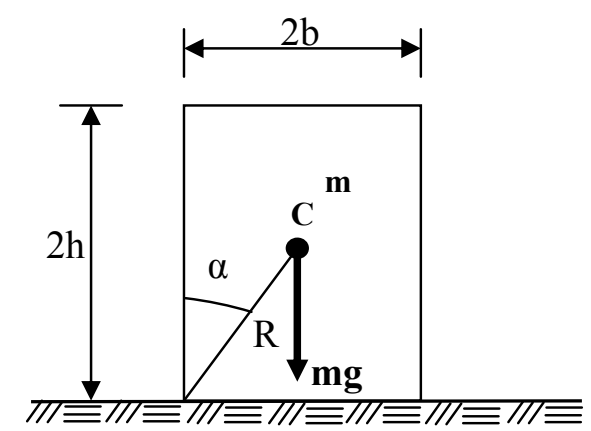

Fig. (1). Free-standing rectangular rigid block under its own weight.

Langrange's equations for rigid body motion of the above rectangular block for the cases of Fig. (2a) and Fig. (2b) are given by $[7,8]$.

$$
\frac{\mathrm{d}}{\mathrm{dt}}\left(\frac{\partial \mathrm{K}}{\partial \dot{\theta}}\right)-\frac{\partial \mathrm{K}}{\partial \theta}+\frac{\partial \Omega}{\partial \theta}=0
$$

where $\mathrm{K}$ is the total kinetic energy and $\Omega$ the potential of the external force $\mathrm{mg}$ (the weight of the block) and $\theta$ the angle of the bock rotation measured from the vertical.

\section{Case 1 (Fig. 2a)}

According to the sign convention of Fig. (2a) the total horizontal displacement of the center of gravity $\mathrm{C}$ of the block, $u_{c}$, due to ground displacement $u_{g}$ is [9]. 


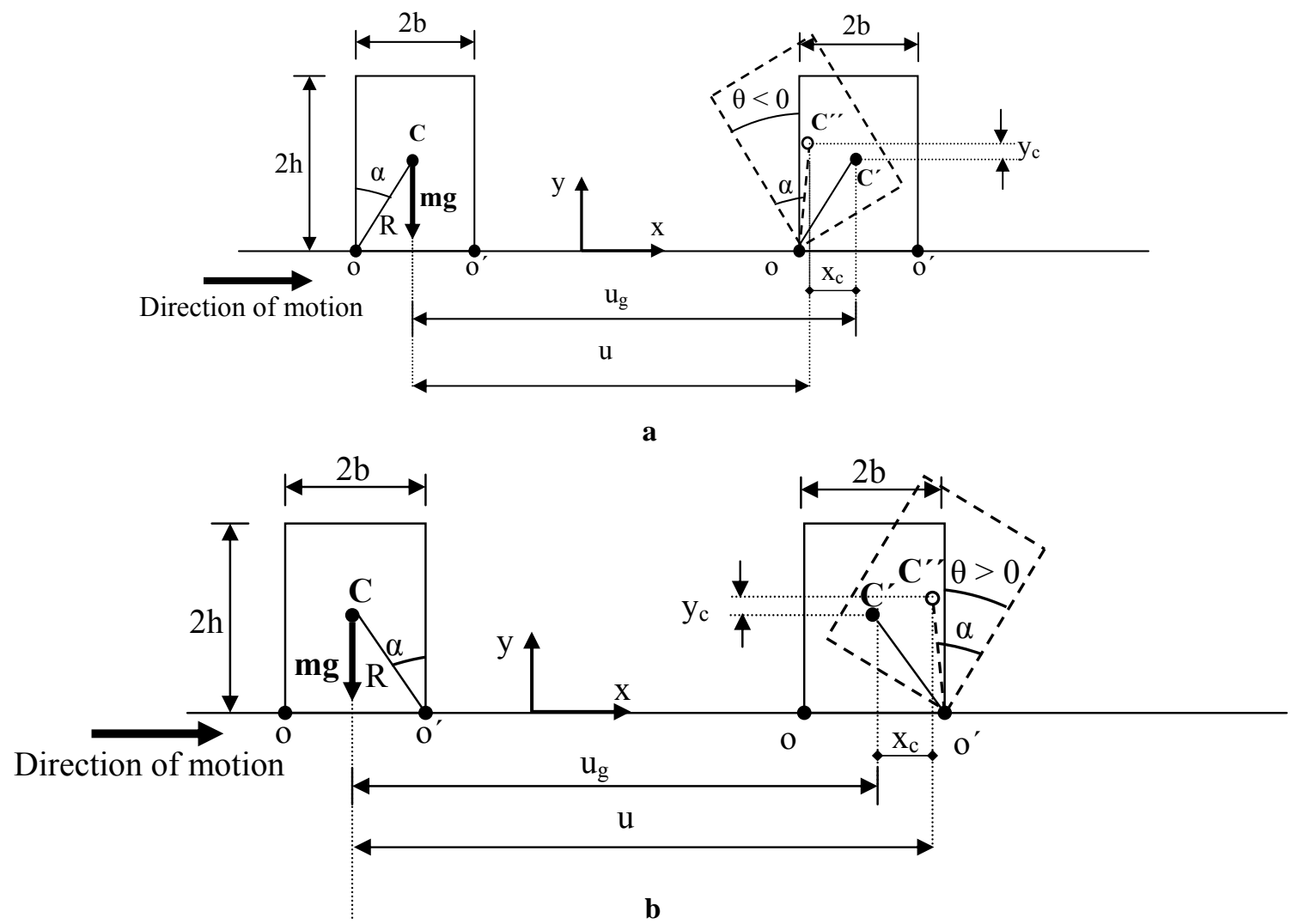

Fig. (2). a. Rigid body block displacement under ground excitation (rather suddenly applied), b. Rigid body block displacement under ground excitation (rather suddenly reduced).

$\mathrm{u}_{\mathrm{c}}=\mathrm{u}_{\mathrm{g}}-\mathrm{x}_{\mathrm{c}}, \mathrm{x}_{\mathrm{c}}=\mathrm{b}-\mathrm{R} \sin (\alpha+\theta) \quad(\theta(\mathrm{t})<0)$

while the vertical displacement of $\mathrm{C}$, is

$\mathrm{y}_{\mathrm{c}}=\mathrm{R}[\cos (\alpha+\theta)-\cos \alpha]$

By virtue of relations (2) and (3) we get

$\dot{\mathrm{u}}_{\mathrm{c}}=\dot{\mathrm{u}}_{\mathrm{g}}+\mathrm{R} \dot{\theta} \cos (\alpha+\theta), \dot{\mathrm{y}}_{\mathrm{c}}=-\mathrm{R} \dot{\theta} \sin (\alpha+\theta)$

The total kinetic energy due to the combined motion of the block (rotation and translation) is

$\mathrm{K}=\frac{1}{2} \mathrm{~J}_{\mathrm{c}} \dot{\theta}^{2}+\frac{1}{2} \mathrm{~m}\left(\dot{\mathrm{u}}_{\mathrm{c}}^{2}+\dot{\mathrm{y}}_{\mathrm{c}}^{2}\right)$

where $J_{c}=m^{2} / 3$ is the polar moment of inertia of the block with respect to its center of gravity $\mathrm{C}$.

Using relations (4), eq. (5) is written as follows

$\mathrm{K}=\frac{1}{2} \mathrm{~J}_{\mathrm{o}} \dot{\theta}^{2}+\frac{1}{2} \mathrm{mu}_{\mathrm{g}}{ }^{2}+\mathrm{mu}_{\mathrm{g}} \dot{\theta} \mathrm{R} \cos (\alpha+\theta)$

where $J_{o}=J_{c}+m^{2}=4 \mathrm{mR}^{2} / 3$ is the polar moment of inertia of the block with respect to the pivot point $\mathrm{O}$.

From eq. (6) it follows that

$\frac{\partial \mathrm{K}}{\partial \dot{\theta}}=\mathrm{J}_{\mathrm{o}} \dot{\theta}+\operatorname{mu}_{\mathrm{g}} \mathrm{R} \cos (\alpha+\theta)$

and $\frac{\mathrm{d}}{\mathrm{dt}}\left(\frac{\partial \mathrm{K}}{\partial \dot{\theta}}\right)=\mathrm{J}_{\mathrm{o}} \ddot{\theta}+\operatorname{mü}_{\mathrm{g}} R \cos (\alpha+\theta)-\operatorname{mu}_{\mathrm{g}} \dot{\theta} \mathrm{R} \sin (\alpha+\theta)$.
From eq. (6) we also obtain

$\frac{\partial \mathrm{K}}{\partial \theta}=-\mathrm{mu}_{\mathrm{g}} \dot{\theta} \mathrm{R} \sin (\alpha+\theta)$.

Given that

$\Omega=\operatorname{mgR}[\cos (\alpha+\theta)-\cos \alpha]$

then

$\frac{\partial \Omega}{\partial \theta}=-m g R \sin (\alpha+\theta)$.

Using relations (7), (8) and (10), eq. (1) becomes

$\mathrm{J}_{\mathrm{o}} \ddot{\theta}+\mathrm{mü}_{\mathrm{g}} \mathrm{R} \cos (\alpha+\theta)-\mathrm{mgR} \sin (\alpha+\theta)=0 \quad(\theta(\mathrm{t})<0)$.

This is the equation of rigid body motion that can be also derived by taking equilibrium of moments of all forces with respect to the pivot point $\mathrm{O}$ (Fig. 3a).

\section{Case 2 (Fig. 2b)}

The total horizontal displacement of the center of gravity $\mathrm{C}$ of the block $\mathrm{u}_{\mathrm{c}}$, due to ground displacement $\mathrm{u}_{\mathrm{g}}$, according to Fig. (2b), is

$u_{c}=u_{g}+x_{c}, x_{c}=b-R \sin (\alpha-\theta)$

while the vertical displacement of $\mathrm{C}$ is

$\mathrm{y}_{\mathrm{c}}=\mathrm{R}[\cos (\alpha-\theta)-\cos \alpha]$ 


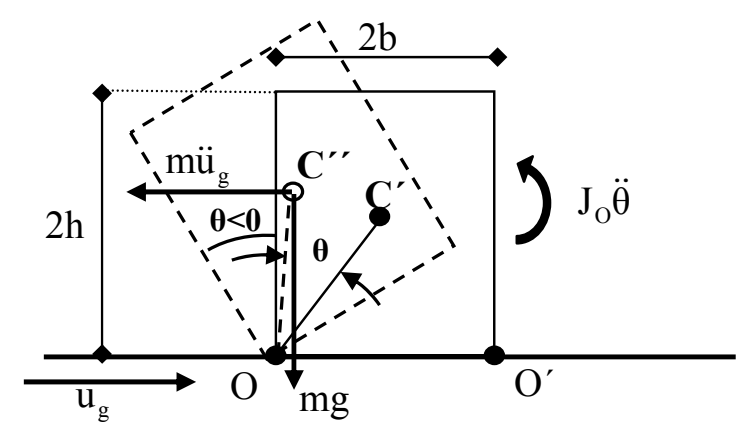

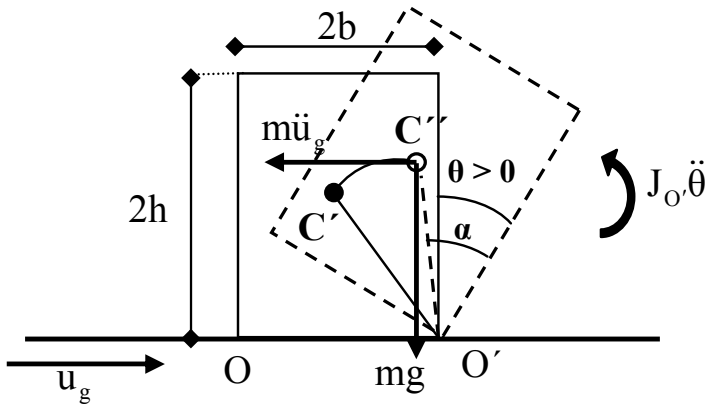

b

Fig. (3). a. Free body diagram of the block related to Fig. (2a), b. Free body diagram of the block related to Fig. (2b).

and the potential due to the external force $\mathrm{mg}$ is equal to

$\Omega=\operatorname{mgR}[\cos (\alpha-\theta)-\cos \alpha]$,

By virtue of relations (12) and (13) we get

$\dot{\mathrm{u}}_{\mathrm{c}}=\dot{\mathrm{u}}_{\mathrm{g}}+\mathrm{R} \dot{\theta} \cos (\alpha-\theta), \dot{\mathrm{y}}_{\mathrm{c}}=\mathrm{R} \dot{\theta} \sin (\alpha-\theta)$.

The kinetic energy due to the combined rigid body motion of the block (rotation and translation about $\mathrm{O}^{\prime}$ ) using relations (15) is

$\mathrm{K}=\frac{1}{2} \mathrm{~J}_{\mathrm{c}} \dot{\theta}^{2}+\frac{\mathrm{m}}{2}\left(\dot{\mathrm{u}}_{\mathrm{c}}^{2}+\dot{\mathrm{y}}_{\mathrm{c}}^{2}\right)=\frac{1}{2} \mathrm{~J}_{\mathrm{o}} \dot{\theta}^{2}+\frac{1}{2} \mathrm{mu}_{\mathrm{g}}{ }^{2}+\mathrm{mR} \dot{\mathrm{u}}_{\mathrm{g}} \dot{\theta} \cos (\alpha-\theta)$

where $J_{o}=J_{c}+m^{2}=4 \mathrm{mR}^{2} / 3$ is the polar moment of inertia of the block about $\mathrm{O}^{\prime}$.

From eq. (16) it follows that

$\frac{\partial \mathrm{K}}{\partial \dot{\theta}}=\mathrm{J}_{\mathrm{o}} \dot{\theta}+\mathrm{mR} \dot{\mathrm{u}}_{\mathrm{g}} \cos (\alpha-\theta)$

and

$\frac{\mathrm{d}}{\mathrm{dt}}\left(\frac{\partial \mathrm{K}}{\partial \dot{\theta}}\right)=\mathrm{J}_{\mathrm{o}} \ddot{\theta}+\mathrm{mR} \ddot{u}_{\mathrm{g}} \cos (\alpha+\theta)+\mathrm{mR} \dot{\mathrm{u}}_{\mathrm{g}} \dot{\theta} \sin (\alpha-\theta)$

Moreover

$\frac{\partial \mathrm{K}}{\partial \theta}=\mathrm{mR}_{\mathrm{g}} \dot{\theta} \sin (\alpha-\theta)$.

Due to relation (14) we get

$\frac{\partial \Omega}{\partial \theta}=\operatorname{mgR} \sin (\alpha-\theta)$.

Using relations (17), (18) and (19), eq. (1) becomes

$\mathrm{J}_{\mathrm{o}} \ddot{\theta}+\mathrm{mR} \ddot{\mathrm{u}}_{\mathrm{g}} \cos (\alpha-\theta)+\mathrm{mgR} \sin (\alpha-\theta)=0 \quad(\theta(\mathrm{t})>0)$.

This equation can also be derived by taking equilibrium of moments of all the above forces about $\mathrm{O}^{\prime}$ (Fig. 3b).

Eqs. (11) and (20) can also be written as follows

$$
\begin{aligned}
& \ddot{\theta}+\mathrm{p}^{2}\left[\frac{\ddot{\mathrm{u}}_{\mathrm{g}}}{\mathrm{g}} \cos (\alpha+\theta)-\sin (\alpha+\theta)\right]=0, \theta(\mathrm{t})<0 \\
& \ddot{\theta}+\mathrm{p}^{2}\left[\frac{\ddot{\mathrm{u}}_{\mathrm{g}}}{\mathrm{g}} \cos (\alpha-\theta)+\sin (\alpha-\theta)\right]=0, \theta(\mathrm{t})>0
\end{aligned}
$$

where $p=\sqrt{3 g / 4 R}$ is a measure of the dynamic characteristic of the block and not the oscillatory frequency under free vibration, because the oscillation frequency in not constant depending strongly on the vibration amplitude [10]. Note that owing to the difference in the last terms of eq. $(21 a, b)$ one can conclude that the magnitude of ground excitation in Fig. (2a) is significantly large (much larger to that corresponding to Fig. 2b).

Regardless of the form of ground excitation there are two possible modes for overturning: (a) overturning without impact and (b) overturning with one impact. Referring to the case of Fig. (2a) the block may overturn under very large ground excitation with $\theta<0$ without impact (mode 1 ). However, for a ground acceleration slightly smaller than the previous one, the block rotates in the reverse direction and impacts on point $\mathrm{O}^{\prime}$ before overturning with $\theta>0$. The minimum acceleration amplitude corresponds to the unstable static equilibrium for which $\theta=\alpha, \dot{\theta}=0$ and $\ddot{\theta}=0$, implying $\ddot{\mathrm{u}}_{\mathrm{g}}=0$ due to eq. (21a); namely, we have overturning instability after one impact. Now referring to the case of Fig. (2b) the block may overturn (on the basis of minimum acceleration amplitude) through the unstable equilibrium position for which $\theta=\alpha, \dot{\theta}=0$ and $\ddot{\theta}=0$, implying $\ddot{\mathrm{u}}_{\mathrm{g}}=0$ due to eq. (21b). Namely, in this case overturning instability occurs without impact; otherwise for a smaller magnitude of excitation the block returns to its initial vertical equilibrium position.

The total energy $\mathrm{E}=\mathrm{K}+\mathrm{U}=\mathrm{K}+\mathrm{V}+\Omega$ corresponding to eq. (21a) and (21b) is

$\mathrm{E}=\frac{1}{2} \mathrm{~J}_{\mathrm{o}} \dot{\theta}^{2}+\frac{1}{2} \mathrm{mu}_{\mathrm{g}}^{2}+\mathrm{mR} \dot{\mathrm{u}}_{\mathrm{g}} \dot{\theta} \cos (\alpha+\theta)+\operatorname{mgR}[\cos (\alpha+\theta)-\cos \alpha]$,

$\theta(\mathrm{t})<0$

$\mathrm{E}=\frac{1}{2} \mathrm{~J}_{\mathrm{o}} \dot{\theta}^{2}+\frac{1}{2} \mathrm{mu}_{\mathrm{g}}^{2}+\mathrm{mR} \dot{\mathrm{u}}_{\mathrm{g}} \dot{\theta} \cos (\alpha-\theta)+\mathrm{mgR}[\cos (\alpha-\theta)-\cos \alpha]$, $\theta(\mathrm{t})>0$.

Clearly, replacing $\theta$ by $-\theta$ in eq. (22a) we obtain eq. (22b).

\section{Condition for Initiation of Rocking Motion}

Consider the rigid block shown in Fig. (4a) with "stockiness" $\alpha$ which can oscillate about the centers of rotation $\mathrm{O}$ and $\mathrm{O}^{\prime}$ when it is set to rocking motion. As assumed above the coefficient of friction is large enough so that there is no sliding. Fig. (4b) shows the moment-rotation relation during the rocking motion of a freely-standing rectangular block. The system has infinite stiffness until the magnitude 


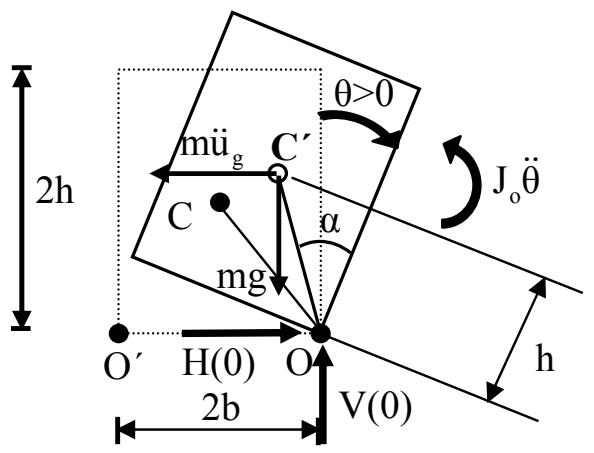

a

Fig. (4). a. Free body diagram of the block.

of the applied moment reaches mgRsin $\alpha$, and once the block is rocking its stiffness decreases gradually becoming zero when $\theta=\alpha$. During the oscillatory rocking motion, the moment-rotation relationship follows the above diagram without losing energy (i.e. enclosing any area). Energy is lost only due to friction (this case has been excluded because it has been assumed that there is no sliding) or during impact, when the angle of rotation reverses. The last case of loss of energy due to impact will be discussed in the next section.

When the block is in vertical equilibrium position the horizontal force $\mathrm{H}$ which is needed to initiate rocking motion is obtained from the condition

$\mathrm{HR} \cos \alpha \geq \mathrm{mgR} \sin \alpha$.

Since $\mathrm{H}=m \ddot{u}_{\mathrm{g}}=m \alpha_{\mathrm{p}}\left(\alpha_{\mathrm{p}}\right.$ is the maximum amplitude), then initiation of rocking yields

$\alpha_{\mathrm{p}} \geq \mathrm{g} \tan \alpha$

and $\alpha_{\mathrm{p}, \min }=\mathrm{g} \tan \alpha$.

This is the minimum amplitude of ground acceleration for the initiation of rocking motion.

Dynamic equilibrium (in horizontal and vertical direction) at the instant $\mathrm{t}=0$, where $\theta(0)=0$, gives (Fig. 5)

$\mathrm{H}(0)=\mathrm{m}\left(\ddot{\mathrm{u}}_{\mathrm{g}}+\mathrm{R} \ddot{\theta}(0) \cos \alpha\right)=\mathrm{m}\left(\lambda \alpha_{\rho}+\mathrm{h} \ddot{\theta}(0)\right)$

$\mathrm{V}(0)=\mathrm{m}(\mathrm{g}-\mathrm{R} \ddot{\theta}(0) \sin \alpha)=\mathrm{m}(\mathrm{g}-\mathrm{b} \ddot{\theta}(0))$

and moments about $\mathrm{C}$

$\mathrm{H}(0) \mathrm{h}-\mathrm{V}(0) \mathrm{b}+\mathrm{J}_{\mathrm{c}} \ddot{\theta}(0)=0$

where $\mathrm{J}_{\mathrm{c}}=\mathrm{mR}^{2} / 3$ and $1 \geq \lambda \geq \mathrm{g} \tan \alpha / \alpha_{\mathrm{p}}$.

Substituting eq. (25) and eq. (26) into eq. (27) we get the angular acceleration at the instant $\mathrm{t}=0$, i.e.

$\ddot{\theta}(0)=p^{2} \sin \alpha\left(1-\frac{\lambda \alpha_{p}}{\operatorname{gtan} \alpha}\right), p^{2}=\frac{3 g}{4 R}$

when rocking initiates.

To avoid sliding at $\mathrm{t}=0$ we must have

$\mu \mathrm{V}(0) \geq \mathrm{H}(0)$

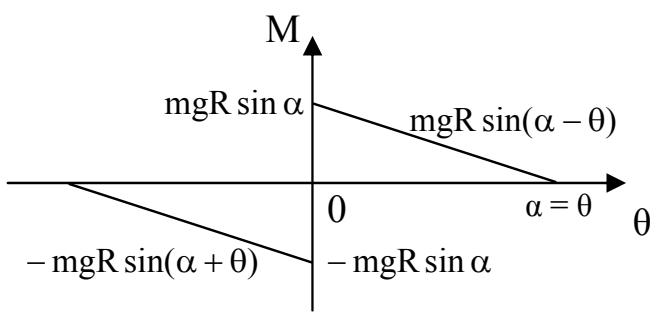

b

b. Moment $\mathrm{M}$ versus rotation $\theta$.

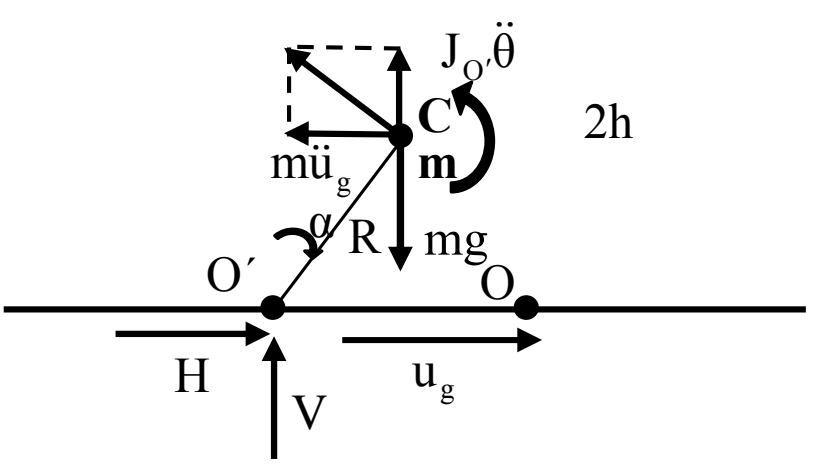

Fig. (5). Dynamic reactions acting on the point $\mathrm{O}^{\prime}$ at the initiation of rocking motion $(t=0)$.

or $\mu \geq \frac{\mathrm{H}(0)}{\mathrm{V}(0)}$.

Inserting $\ddot{\theta}(0)$ from eq. (28) into eqs. (25) and (26), inequality (30) becomes [1,2]

$\mu \geq \frac{\lambda \alpha_{\rho}-\frac{3}{4} \mathrm{~g} \cos \alpha \sin \alpha\left(\frac{\lambda \alpha_{\rho}}{\mathrm{g} \tan \alpha}-1\right)}{\mathrm{g}+\frac{3}{4} \mathrm{~g} \sin ^{2} \alpha\left(\frac{\lambda \alpha_{\rho}}{\mathrm{g} \tan \alpha}-1\right)}$.

This is the condition required for a block to enter the rocking motion without sliding.

According to previous work [1,2], inequality (31) shows that, under some ground excitations with amplitude $\alpha_{\mathrm{p}}$, the condition for a block to enter rocking motion without sliding depends on the value $\alpha_{\mathrm{p}}$. However, for pulses in which acceleration increases gradually from zero (like one-sine pulse) the value of $\lambda \alpha_{\rho}$ at the initiation of rocking motion is equal to $g \tan \alpha$ and eq. (31) reduces to the expression defined from static equilibrium, i.e.

$\mu \geq \frac{\mathrm{b}}{\mathrm{h}}=\tan \alpha$.

Once the block enters rocking motion, both dynamic reactions $\mathrm{H}(\mathrm{t})$ and $\mathrm{V}(\mathrm{t})$ fluctuate with time. Hence, to avoid sliding during the entire rocking motion we must have at all times 

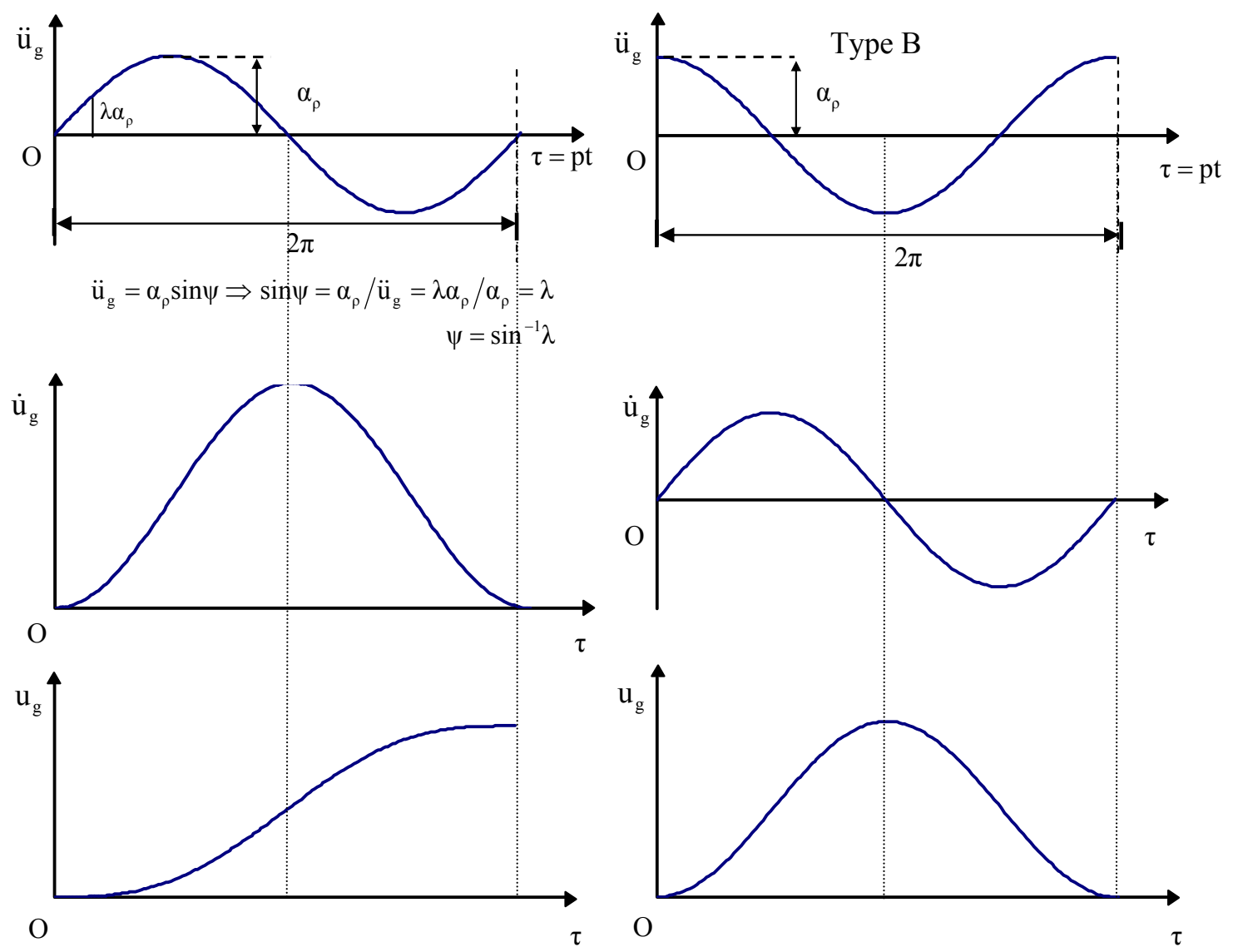

Fig. (6). Acceleration, velocity and displacement histories of one-sine (left) and one-cosine (right) pulse.

$\mu>\frac{\mathrm{H}(\mathrm{t})}{\mathrm{V}(\mathrm{t})}$

In Fig. (6) one can see acceleration, velocity and displacement histories of one-sine pulse (left) and one-cosine pulse (right) [4]. In the first case (Type A) the ground acceleration is zero at the starting of motion and increases gradually. In contrast, in the second case (Type B) the ground acceleration assumes its maximum at the initiation of motion. Under other pulses, e.g. type- $C_{n}$ pulses [3], the ground acceleration is finite at the initiation of rocking motion but assumes a value that is smaller than its maximum amplitude $\alpha_{\mathrm{p}}$.

\section{Loss of Energy During Impact}

When the angle of rotation reverses we assume that such a rotation continues smoothly from point $\mathrm{O}$ to point $\mathrm{O}^{\prime}$ (Fig. 7). We consider an impact without bouncing so that the block switches pivot points (from $\mathrm{O}$ to $\mathrm{O}^{\prime}$ ), while the angular momentum is conserved. If the coefficient of restitution is e the ratio of the angular speed of the block immediately after impact $\dot{\theta}_{+}$, to the angular speed immediately before impact $\dot{\theta}_{-}$according to [11] is

$\mathrm{e}=\frac{\dot{\theta}_{+}}{\dot{\theta}_{-}}$.

Clearly $\left|\dot{\theta}_{-}\right|>\left|\dot{\theta}_{+}\right|$. The energy lost is $E_{\mathrm{L}}$, i.e.

$$
\begin{aligned}
& \mathrm{E}_{\mathrm{L}}=\frac{1}{2} \mathrm{~J}_{\mathrm{o}} \dot{\theta}_{-}^{2}-\frac{1}{2} \mathrm{~J}_{\mathrm{o}} \dot{\theta}_{+}^{2}=\frac{2}{3} \mathrm{mR}^{2}\left(\dot{\theta}_{-}^{2}-\dot{\theta}_{+}^{2}\right) \\
& \text { or } \mathrm{E}_{\mathrm{L}}=\frac{2}{3} \mathrm{mR}^{2} \dot{\theta}_{-}^{2}\left(1-\mathrm{e}^{2}\right) .
\end{aligned}
$$

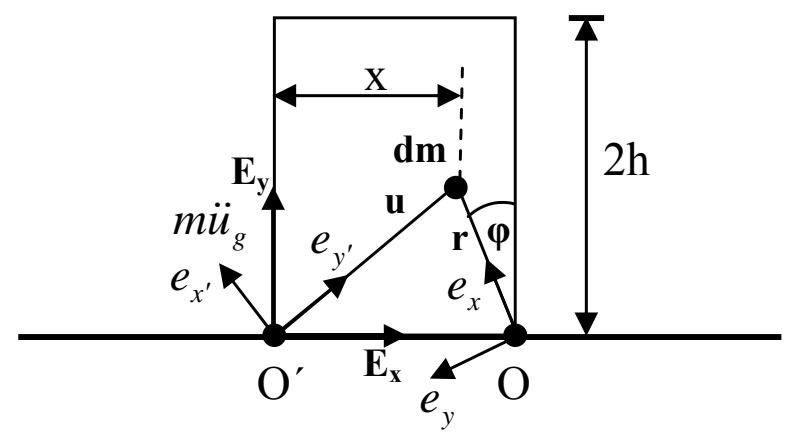

Fig. (7). Rectangular block under rocking motion just before it impacts on point $\mathrm{O}^{\prime}$.

Fig. (7) shows the rectangular block of uniform density $\rho$, $[\rho(2 \mathrm{~h} \times 2 \mathrm{~b})]=\mathrm{m}$, that is rotating about $\mathrm{O}$ and is about to impact at point $\mathrm{O}^{\prime}$. Consider firstly the angular momentum of the block about $\mathrm{O}^{\prime}$ before impact. A mass element $\mathrm{dm}$ located at a distance $r$ from point $\mathrm{O}$ has a velocity $v_{-}=\dot{r}_{-} \mathrm{e}_{\mathrm{y}}$. The position of the mass element is $u=2 b_{x}+r_{x}$, and hence the angular momentum of the block $\mathrm{B}$ about $\mathrm{O}^{\prime}$ before the impact is 
$\mathrm{H}_{-}^{\mathrm{O}^{\prime}}=\int_{\mathrm{B}} \mathrm{uxv}_{-} \mathrm{dm}$.

Taking into account that

$e_{x} x_{y}=\left|e_{x}\right|\left|e_{y}\right| \sin \frac{\pi}{2} e_{z}=e_{z}$,

$\mathrm{E}_{\mathrm{x}} \mathrm{xe}_{\mathrm{y}}=-\left|\mathrm{e}_{\mathrm{x}}\right|\left|\mathrm{e}_{\mathrm{y}}\right| \sin \phi \cdot \mathrm{e}_{\mathrm{z}}=-\sin \phi \cdot \mathrm{e}_{\mathrm{z}}$

eq. (36) becomes

$\mathrm{H}_{-}^{\mathrm{O}^{\prime}}=\left(\int_{B}\left(\mathrm{r}^{2}-2 \mathrm{brsin} \varphi\right) \mathrm{dm}\right) \dot{\theta}_{-} \mathrm{e}_{\mathrm{z}}$.

Since $d m=\rho d x d y, r \sin \phi=2 b-x$

then $H_{-}^{O^{\prime}}=\left(\rho \int_{0}^{2 b} \int_{0}^{2 h}\left[r^{2}-2 b(2 b-x)\right] d x d y\right) \dot{\theta}_{-} e_{z}$.

Given that

$r^{2}=y^{2}+(2 b-x)^{2}, r^{2}-2 b(2 b-x)=x^{2}+y^{2}-2 b x$

then

$\int_{0}^{2 b} \int_{0}^{2 h}\left[x^{2}+y^{2}-2 b x\right] d x d y=4 h b\left(\frac{4}{3} h^{2}-\frac{2}{3} b^{2}\right)$.

Since $b=R \sin \alpha$

and $4 h b\left(\frac{4}{3} h^{2}-\frac{2}{3} b^{2}\right)=4 h b\left(\frac{4}{3} R^{2}-2 R^{2} \sin ^{2} \alpha\right)$

by virtue of relations (41) and (42), eq(39) becomes

$\mathrm{H}^{\mathrm{O}^{\prime}}=\left(\rho \int_{0}^{2 \mathrm{~b}} \int_{0}^{2 \mathrm{~b}}\left[\mathrm{r}^{2}-2 \mathrm{~b}(2 \mathrm{~b}-\mathrm{x})\right] \mathrm{dxdy}\right) \dot{\theta}_{-} \mathrm{e}_{\mathrm{z}}$

or $\mathrm{H}_{-}^{\mathrm{O}^{\prime}}=\mathrm{mR}^{2}\left(\frac{4}{3}-2 \sin ^{2} \alpha\right) \dot{\theta}_{-} \mathrm{e}_{\mathrm{z}}$.

The position of the infinitesimal mass element $\mathrm{dm}$ immediately after impact is $u=r e_{x}$, and its velocity $v_{+}=r \dot{\theta}_{+} e_{y}$. Thus, the angular momentum of the block B about $\mathrm{O}$ after impact is

$\mathrm{H}_{+}^{\mathrm{O}^{\prime}}=\int_{\mathrm{B}} \mathrm{uxv}_{+} \mathrm{dm}$

or $\mathrm{H}_{+}^{\mathrm{O}^{\prime}}=\left(\int_{\mathrm{B}} \mathrm{r}^{2} \mathrm{dm}\right) \dot{\theta}_{+} \mathrm{e}_{\mathrm{z}}=\frac{4}{3} \mathrm{mR}^{2} \dot{\theta}_{+} \mathrm{e}_{\mathrm{z}}$.

Conservation of angular momentum, $\mathrm{H}_{-}^{\mathrm{O}^{\prime}}=\mathrm{H}_{+}^{\mathrm{O}^{\prime}}$, due to relations (42) and (45), yields

$$
\begin{aligned}
& \left(1-\frac{3}{2} \sin ^{2} \alpha\right) \dot{\theta}_{-}=\dot{\theta}_{+} \\
& \text {or } \mathrm{e}=\frac{\dot{\theta}_{+}}{\dot{\theta}_{-}}=1-\frac{3}{2} \sin ^{2} \alpha .
\end{aligned}
$$

This value of e (depending only on the geometry of the block) is the maximum value of the coefficient of restitution for which a block of stockiness $\alpha$ will undergo rocking motion [4]. Since $\mathrm{e}_{\max }<1$ the impact is inelastic. Since the angular momentum is not actually conserved during impact the value of e can only be thought of as a rough approximation because it's precise value depends on the contact region and the corresponding material properties. The value of e can be obtained experimentally. For the stockiness $\alpha=\tan ^{-1}(\mathrm{~b} / \mathrm{h})=$ $\tan ^{-1}(0.11)$ of the statues in the Academy of Athens, eq. (46) gives $\mathrm{e}=0.982[9]$.

\section{Condition for Rocking Motion}

When the block is rocking the horizontal and vertical reactions at point $\mathrm{O}$ and $\mathrm{O}^{\prime}$ are varying with time. Dynamic equilibrium in both directions yields (Figs. 3a and 5)

$H(t)=m\left[\ddot{u}_{g}(t)-\ddot{x}_{c}(t)\right], V(t)=m\left[g-\ddot{y}_{c}(t)\right]$

Since for $\theta(\mathrm{t})<0, \mathrm{x}_{\mathrm{c}}=\mathrm{b}-\mathrm{R} \sin (\alpha+\theta), \dot{\mathrm{x}}_{\mathrm{c}}=-\mathrm{R} \dot{\theta} \cos (\alpha+\theta)$

and $\ddot{x}_{c}=-\ddot{\theta} R \cos (\alpha+\theta)+\dot{\theta}^{2} R \sin (\alpha+\theta)$

Similarly

$\mathrm{y}_{\mathrm{c}}=\mathrm{R}[\cos (\alpha+\theta)-\cos \alpha], \dot{\mathrm{y}}_{\mathrm{c}}=-\mathrm{R} \dot{\theta}[\sin (\alpha+\theta)]$

and $\ddot{y}_{c}=-\ddot{\theta} R \sin (\alpha+\theta)-\dot{\theta}^{2} R \cos (\alpha+\theta)$

where $\dot{\theta}(\mathrm{t})$ is the angular velocity of the block and $\ddot{\theta}(\mathrm{t})$ is the angular acceleration of the block given by eq. (21a) [2].

Substituting eqs. (47) into inequality (33) and using eqs. (11), (48) and (49) allows us to establish the condition for excluding sliding during the entire rocking motion, i.e.

$\frac{\mathrm{H}(\mathrm{t})}{\mathrm{V}(\mathrm{t})}=\frac{\ddot{\mathrm{u}}_{\mathrm{g}}-\mathrm{p}^{2} \mathrm{R}\left[\frac{\ddot{\mathrm{u}}_{\mathrm{g}}}{\mathrm{g}} \cos ^{2}(\alpha+\theta)-\frac{1}{2} \sin 2(\alpha+\theta)+\frac{\dot{\theta}^{2}}{\mathrm{p}^{2}} \sin (\alpha+\theta)\right]}{\mathrm{g}-\mathrm{p}^{2} \mathrm{R}\left[\frac{\ddot{\mathrm{u}}_{\mathrm{g}}}{\mathrm{g}} \sin 2(\alpha+\theta)-\sin ^{2}(\alpha+\theta)-\frac{\dot{\theta}^{2}}{\mathrm{p}^{2}} \cos (\alpha+\theta)\right]} \leq \mu$

At the initiation ( $\mathrm{t}=0$ ) of rocking, $\theta(0)=\dot{\theta}(0)=0$, while - as shown above - the minimum acceleration must be $\ddot{\mathrm{u}}_{\mathrm{g}}=\mathrm{g} \tan \alpha$. Clearly at $\mathrm{t}=0$, eq. (50) gives

$\frac{\mathrm{H}(0)}{\mathrm{V}(0)}=\frac{\ddot{\mathrm{u}}_{\mathrm{g}}}{\mathrm{g}}=\tan \alpha \leq \mu$.

\section{Linear Approximation Under One-Sine Pulse}

On the basis of the type A of one- sine pulse (Fig. 6, left) one can write the following ground acceleration

$\ddot{\mathrm{u}}_{\mathrm{g}}(\mathrm{t})=\alpha_{\mathrm{p}} \sin \left(\omega_{\mathrm{p}} \mathrm{t}+\psi\right),-\psi / \omega_{\mathrm{p}} \leq \mathrm{t} \leq(2 \pi-\psi) / \omega_{\mathrm{p}}$,

otherwise, $\ddot{\mathrm{u}}_{\mathrm{g}}(\mathrm{t})=0$.

Clearly

$\ddot{\mathrm{u}}_{\mathrm{g}}(0)=\alpha_{\mathrm{p}} \sin \psi=\lambda \alpha_{\mathrm{p}}$ or $\psi=\sin ^{-1} \lambda$.

Since $\lambda \alpha_{p}=g \tan \alpha$, then 


$$
\psi=\sin ^{-1}\left(\frac{\operatorname{gtan} \alpha}{\alpha_{p}}\right)
$$

According to eq. (32) the block enters into pure rocking when

$\tan \alpha=\frac{\mathrm{b}}{\mathrm{h}}<\mu$.

For slender blocks with $\mathrm{b} / \mathrm{h} \leq 0.25$, eqs. $(21 \mathrm{a}, \mathrm{b})$ can $\mathrm{be}$ linearized as follows

$\ddot{\theta}-\mathrm{p}^{2} \theta=\mathrm{p}^{2} \alpha-\mathrm{p}^{2} \frac{\alpha_{\mathrm{p}}}{\mathrm{g}} \sin \left(\omega_{\mathrm{p}} \mathrm{t}+\psi\right) \quad(\theta(\mathrm{t})<0)$

$\ddot{\theta}-\mathrm{p}^{2} \theta=-\mathrm{p}^{2} \alpha-\mathrm{p}^{2} \frac{\alpha_{\mathrm{p}}}{\mathrm{g}} \sin \left(\omega_{\mathrm{p}} \mathrm{t}+\psi\right) \quad(\theta(\mathrm{t})>0)$.

Integration of eqs. (56a,b) gives

for $\theta(\mathrm{t})<0$

$\theta=A_{1} \operatorname{sinhpt}+A_{2} \operatorname{coshpt}+\frac{1}{1+\omega_{p}{ }^{2} / p^{2}} \frac{\alpha_{p}}{g} \sin \left(\omega_{p} t+\psi\right)-\alpha$

for $\theta(t)>0$

$\theta=A_{3} \sinh p t+A_{4} \operatorname{coshpt}+\frac{1}{1+\omega_{p}^{2} / p^{2}} \frac{\alpha_{p}}{g} \sin \left(\omega_{p} t+\psi\right)+\alpha \cdot$

For the initial condition $\theta(0)=\theta_{0}$ and $\dot{\theta}(0)=\dot{\theta}_{\mathrm{o}}$ we get

$\mathrm{A}_{1}=\frac{\dot{\theta}_{0}}{\mathrm{p}}-\alpha \frac{\omega_{\mathrm{p}} / \mathrm{p}}{1+\omega_{\mathrm{p}}^{2} / \mathrm{p}^{2}} \cot \psi, \mathrm{A}_{2}=\theta_{0}+\alpha-\frac{\alpha}{1+\omega_{\mathrm{p}}^{2} / \mathrm{p}^{2}}$,

$\mathrm{A}_{3}=\frac{\dot{\theta}_{0}}{\mathrm{p}}-\alpha \frac{\omega_{\mathrm{p}} / \mathrm{p}}{1+\omega_{\mathrm{p}}^{2} / \mathrm{p}^{2}} \cot \psi, \mathrm{A}_{4}=\theta_{0}-\alpha-\frac{\alpha}{1+\omega_{\mathrm{p}}^{2} / \mathrm{p}^{2}}$

The derivatives of eqs. $(57 \mathrm{a}, \mathrm{b})$ are

$\frac{\dot{\theta}}{\mathrm{p}}=\mathrm{A}_{1} \cosh \mathrm{pt}+\mathrm{A}_{2} \sinh \mathrm{pt}+\alpha \frac{\omega_{\mathrm{p}} / \mathrm{p}}{1+\omega_{\mathrm{p}}^{2} / \mathrm{p}^{2}} \frac{\cos \left(\omega_{\mathrm{p}} \mathrm{t}+\psi\right)}{\sin \psi}$

$\frac{\dot{\theta}}{\mathrm{p}}=\mathrm{A}_{3} \cosh \mathrm{pt}+\mathrm{A}_{4} \sinh \mathrm{pt}+\alpha \frac{\omega_{\mathrm{p}} / \mathrm{p}}{1+\omega_{\mathrm{p}}^{2} / \mathrm{p}^{2}} \frac{\cos \left(\omega_{\mathrm{p}} \mathrm{t}+\psi\right)}{\sin \psi}$.

Using eqs. (57a,b) and (59a,b) one can determine the minimum amplitude acceleration provided that one can establish a condition for overturning instability.

\section{Condition for Overturning Instability}

Attention is focused on the minimum amplitude acceleration leading to overturning instability. Regardless of the type of ground motion such a critical state may occur at some time $\mathrm{t}=\mathrm{t}^{*}$ only through the unstable equilibrium position $\theta\left(\mathrm{t}^{*}\right)=\alpha$. Given that we are searching for the minimum amplitude acceleration which leads to overturning, the conditions for overturning instability are defined by

$\theta\left(\mathrm{t}^{*}\right)=\alpha, \dot{\theta}\left(\mathrm{t}^{*}\right)=0$.

This is so because in such a critical case we may assume that the block can oscillate for a short period of time with an average amplitude $\theta(t)=\alpha$ (e.g. about the unstable equilib- rium position) and thus when $\dot{\theta}\left(\mathrm{t}^{*}\right)=\alpha$ also $\theta\left(\mathrm{t}^{*}\right)=0$. Apparently for $\mathrm{t} \leq \mathrm{t}^{*}$ the block is subjected to free vibrations with initial conditions at $\mathrm{t}=\mathrm{t}_{\mathrm{o}}$ either the end conditions of the forced motion or the impact conditions.

\section{Free Vibration}

In this case eqs. $(56 \mathrm{a}, \mathrm{b})$ become

$\ddot{\theta}-\mathrm{p}^{2} \theta=\mathrm{p}^{2} \alpha$

$\ddot{\theta}-\mathrm{p}^{2} \theta=-\mathrm{p}^{2} \alpha$

which upon integration yield

$\theta=\overline{\mathrm{A}}_{1} \sinh \mathrm{p}\left(\mathrm{t}-\mathrm{t}_{\mathrm{o}}\right)+\overline{\mathrm{A}}_{2} \cosh \mathrm{p}\left(\mathrm{t}-\mathrm{t}_{\mathrm{o}}\right)-\alpha$

$\theta=\overline{\mathrm{A}}_{3} \sinh \mathrm{p}\left(\mathrm{t}-\mathrm{t}_{\mathrm{o}}\right)+\overline{\mathrm{A}}_{4} \cosh \mathrm{p}\left(\mathrm{t}-\mathrm{t}_{\mathrm{o}}\right)+\alpha$

with corresponding angular velocities

$\dot{\theta}\left(\mathrm{t}_{\mathrm{o}}\right) / \mathrm{p}=\overline{\mathrm{A}}_{1} \cosh \mathrm{p}\left(\mathrm{t}-\mathrm{t}_{\mathrm{o}}\right)+\overline{\mathrm{A}}_{2} \sinh \mathrm{p}\left(\mathrm{t}-\mathrm{t}_{\mathrm{o}}\right)$

$\dot{\theta}\left(\mathrm{t}_{\mathrm{o}}\right) / \mathrm{p}=\overline{\mathrm{A}}_{3} \cosh \mathrm{p}\left(\mathrm{t}-\mathrm{t}_{\mathrm{o}}\right)+\overline{\mathrm{A}}_{4} \sinh \mathrm{p}\left(\mathrm{t}-\mathrm{t}_{\mathrm{o}}\right)$

where

$\overline{\mathrm{A}}_{1}=\dot{\theta}\left(\mathrm{t}_{\mathrm{o}}\right) / \mathrm{p}, \overline{\mathrm{A}}_{2}=\theta\left(\mathrm{t}_{0}\right)+\alpha, \overline{\mathrm{A}}_{3}=\dot{\theta}\left(\mathrm{t}_{0}\right) / \mathrm{p}, \overline{\mathrm{A}}_{4}=\theta\left(\mathrm{t}_{0}\right)-\alpha$.

Subsequently, the particular case of overturning under the type A of a one-sine pulse ground acceleration is considered. Two modes of overturning instability are examined: Mode 1 with no impact and mode 2 with one impact.

\section{Mode 1 (no impact)}

Both cases shown in Fig. $(\mathbf{2} \mathbf{a}, \mathbf{b})$ with their corresponding equations of free vibration motion occurring at $\mathrm{t} \geq \mathrm{t}_{\mathrm{o}}=\mathrm{T}_{\mathrm{ex}}=(2 \pi-\psi) / \omega_{\mathrm{p}}$ are considered.

Application of the overturning instability criterion, eqs. (60), for the case of Fig. (2a) related to eqs. (62a \& 63a), yields

$$
\begin{aligned}
& \theta(\mathrm{t})=-\alpha=\overline{\mathrm{A}}_{1} \sinh \mathrm{p}\left(\mathrm{t}-\mathrm{T}_{\mathrm{ex}}\right)+\overline{\mathrm{A}}_{2} \cosh \mathrm{p}\left(\mathrm{t}-\mathrm{T}_{\mathrm{ex}}\right)-\alpha \\
& \dot{\theta}(\mathrm{t}) / \mathrm{p}=0=\overline{\mathrm{A}}_{1} \cosh \mathrm{p}\left(\mathrm{t}-\mathrm{T}_{\mathrm{ex}}\right)+\overline{\mathrm{A}}_{2} \sinh \mathrm{p}\left(\mathrm{t}-\mathrm{T}_{\mathrm{ex}}\right)
\end{aligned}
$$

where according to relations (64)

$\overline{\mathrm{A}}_{1}=\dot{\theta}\left(\mathrm{T}_{\mathrm{ex}}\right) / \mathrm{p}, \overline{\mathrm{A}}_{2}=\theta\left(\mathrm{T}_{\mathrm{ex}}\right)+\alpha$.

Eqs. $(65 a, b)$ have the nontrivial solution

$\overline{\mathrm{A}}_{1}=-\overline{\mathrm{A}}_{2}$

if $\operatorname{tanhp}\left(\mathrm{t}-\mathrm{T}_{\mathrm{ex}}\right)=1$ which may occur at large time. Eq. (67) due to relation (66) yields

$$
\dot{\theta}\left(\mathrm{T}_{\mathrm{ex}}\right)+\mathrm{p}\left(\theta\left(\mathrm{T}_{\mathrm{ex}}\right)+\alpha\right)=0
$$

where $\dot{\theta}\left(\mathrm{T}_{\mathrm{ex}}\right)$ and $\theta\left(\mathrm{T}_{\mathrm{ex}}\right)$ are determined from eqs. (57a) and (59a) which give

$\theta\left(T_{e x}\right)=A_{1} \sinh p T_{e x}+A_{2} \operatorname{coshp} T_{e x}-\alpha$

$\dot{\theta}\left(\mathrm{T}_{\mathrm{ex}}\right) / \mathrm{p}=\mathrm{A}_{1} \operatorname{coshp} \mathrm{T}_{\mathrm{ex}}+\mathrm{A}_{2} \sinh \mathrm{p} \mathrm{T}_{\mathrm{ex}}+\frac{\alpha \omega_{\mathrm{p}} / \mathrm{p}}{1+\omega_{\mathrm{p}}^{2} / \mathrm{p}^{2}} \frac{1}{\sin \psi}$ 
where $A_{1}$ and $A_{2}$ are taken from relations (58) after setting $\theta(0)=\theta_{\mathrm{o}}=0$ and $\dot{\theta}(0)=\dot{\theta}_{\mathrm{o}}=0$, being equal to

$\mathrm{A}_{1}=-\alpha \frac{\omega_{\mathrm{p}} / \mathrm{p}}{1+\omega_{\mathrm{p}}^{2} / \mathrm{p}^{2}} \cot \psi, \mathrm{A}_{2}=\frac{\alpha \omega_{\mathrm{p}}^{2} / \mathrm{p}^{2}}{1+\omega_{\mathrm{p}}^{2} / \mathrm{p}^{2}}$

Introducing expressions (69a, b) into eq(68) and using relations (70) we obtain [Zhang and Makris (2001)]

$\cos \psi-\frac{\omega_{\mathrm{p}}}{\mathrm{p}} \sin \psi=\mathrm{e}^{-\frac{(2 \pi-\psi)}{\omega_{\mathrm{p}} / \mathrm{p}}}$.

Eq. (71) yields the minimum amplitude acceleration $\alpha_{p} / g \alpha=1 / \sin \psi$ for overturning instability for the case of

Fig. (2a), a solution compatible with eq. (65a) implying $\theta(\mathrm{t})<0$ from the beginning of the motion (as anticipated).

Similarly one can proceed for the case of Fig. (2b) related to eqs. (62b) and (63b). Application of the overturning instability criterion (60) leads to

$\theta(\mathrm{t})=\alpha=\overline{\mathrm{A}}_{3} \sinh \mathrm{p}\left(\mathrm{t}-\mathrm{T}_{\mathrm{ex}}\right)+\overline{\mathrm{A}}_{4} \cosh \mathrm{p}\left(\mathrm{t}-\mathrm{T}_{\mathrm{ex}}\right)+\alpha$

$\dot{\theta}(\mathrm{t}) / \mathrm{p}=0=\overline{\mathrm{A}}_{3} \cosh \mathrm{p}\left(\mathrm{t}-\mathrm{T}_{\mathrm{ex}}\right)+\overline{\mathrm{A}}_{4} \sinh \mathrm{p}\left(\mathrm{t}-\mathrm{T}_{\mathrm{ex}}\right)$

where according to relation (64)

$\overline{\mathrm{A}}_{3}=\dot{\theta}\left(\mathrm{T}_{\mathrm{ex}}\right) / \mathrm{p}, \overline{\mathrm{A}}_{4}=\theta\left(\mathrm{T}_{\mathrm{ex}}\right)-\alpha$.

Eqs. (72a,b) have the non-trivial solution

$\overline{\mathrm{A}}_{3}=-\overline{\mathrm{A}}_{4}$

provided that $\tanh p\left(\mathrm{t}-\mathrm{T}_{\mathrm{ex}}\right)=1$ occurring at large time. Eq. (74) due to relations (73) yields

$$
\dot{\theta}\left(\mathrm{T}_{\mathrm{ex}}\right)+\mathrm{p}\left(\theta\left(\mathrm{T}_{\mathrm{ex}}\right)-\alpha\right)=0
$$

where $\dot{\theta}\left(\mathrm{T}_{\mathrm{ex}}\right)$ and $\theta\left(\mathrm{T}_{\mathrm{ex}}\right)$ are determined from eqs. (57b) and (59b) which give

$\theta\left(\mathrm{T}_{\mathrm{ex}}\right)=\mathrm{A}_{3} \sinh \mathrm{p} \mathrm{T}_{\mathrm{ex}}+\mathrm{A}_{4} \cosh \mathrm{p} \mathrm{T}_{\mathrm{ex}}+\alpha$

$\dot{\theta}\left(\mathrm{T}_{\mathrm{ex}}\right) / \mathrm{p}=\mathrm{A}_{3} \operatorname{coshp} \mathrm{T}_{\mathrm{ex}}+\mathrm{A}_{4} \sinh \mathrm{p} \mathrm{T}_{\mathrm{ex}}+\frac{\alpha \omega_{\mathrm{p}} / \mathrm{p}}{1+\omega_{\mathrm{p}}^{2} / \mathrm{p}^{2}} \cdot \frac{1}{\sin \psi}$

where $A_{3}$ and $A_{4}$ are taken from relations (58) after setting $\theta(0)=\theta_{\mathrm{o}}=0$ and $\dot{\theta}(0)=\dot{\theta}_{\mathrm{o}}=0$, i.e.

$\mathrm{A}_{3}=-\alpha \frac{\omega_{\mathrm{p}} / \mathrm{p}}{1+\omega_{\mathrm{p}}^{2} / \mathrm{p}^{2}} \cot \psi, \mathrm{A}_{4}=-\frac{\alpha\left(2+\omega_{\mathrm{p}}^{2} / \mathrm{p}^{2}\right)}{1+\omega_{\mathrm{p}}^{2} / \mathrm{p}^{2}}$.

Introducing expressions $(76 \mathrm{a}, \mathrm{b})$ into eq(75) and using relations (77) we obtain the following result presented for the first time in the relevant literature,

$\left(\frac{\omega_{p}}{p}+\frac{2 p}{\omega_{p}}\right) \sin \psi+\cos \psi=e^{-\frac{(2 \pi-\psi)}{\omega_{p} / p}}$.

Eq. (78) yields the minimum amplitude ground acceleration, $\alpha_{\mathrm{p}} / \mathrm{g} \alpha=1 / \sin \psi$, for overturning instability for the case of Fig. (2b). However, such a solution is not physically ac- ceptable as it implies that Eq.72a is not valid yielding $\theta(\mathrm{t})<0$ instead of $\theta(t)>0$ according to case corresponding to Fig. (2b).

From both the above two cases it is concluded that for the one-sine ground excitation form only the case corresponding to Fig. (2a) is possible (i.e. eq. (71)) while that corresponding to Fig. (2b) (i.e. eq. (78)) is physically unacceptable. Note also that if the ground acceleration in eq. (52) is negative (i.e. $\ddot{\mathrm{u}}_{\mathrm{g}}=-\alpha_{\mathrm{p}} \sin \left(\omega_{\mathrm{p}} \mathrm{t}+\psi\right)$ ) then eq. (71) is again valid (due to the symmetry of the block's in connection with the direction of the ground excitation). However, the important question which now arises is whether the case shown in Fig. (2b) may occur with a suddenly applied positive acceleration $\ddot{u}_{\mathrm{g}}$ which decreases for $\mathrm{t}>0$. This case will be discussed at the end of this section in connection with the effect of initial conditions on the minimum amplitude acceleration.

\section{Mode 2 (one impact)}

Two cases are examined: in the $1^{\text {st }}$ case impact occurs before the ground excitation expires (i.e. at $t_{i}<T_{e x}$ ) and in the $2^{\text {nd }}$ case impact occurs after the excitation expires (i.e. at $\left.t_{i}>T_{e x}\right)$. However, in both cases the conditions of overturning instability (60) (occurring under the free vibrations regime) are still valid. Since we are looking for the minimum excitation amplitude, eq. (75) is also valid.

Case $1\left(t_{i}<T_{e x}\right)$

After one impact occurring before the excitation expires the block is rotating with $\theta(\mathrm{t})>0$. Hence, the equation of motion for $t_{i} \leq t \leq T_{e x}$ can be derived from equation (57b) and (59b), i.e.

$$
\begin{aligned}
& \theta(\mathrm{t})=\mathrm{A}_{3} \sinh \mathrm{p}\left(\mathrm{t}-\mathrm{t}_{\mathrm{i}}\right)+\mathrm{A}_{4} \operatorname{coshp}\left(\mathrm{t}-\mathrm{t}_{\mathrm{i}}\right)+ \\
& \frac{\alpha}{1+\omega_{\mathrm{p}}{ }^{2} / \mathrm{p}^{2}} \frac{\sin \left(\omega_{\mathrm{p}} \mathrm{t}+\psi\right)}{\sin \psi}+\alpha \\
& \frac{\dot{\theta}(\mathrm{t})}{\mathrm{p}}=\mathrm{A}_{3} \cosh \mathrm{p}\left(\mathrm{t}-\mathrm{t}_{\mathrm{i}}\right)+\mathrm{A}_{4} \sinh \mathrm{p}\left(\mathrm{t}-\mathrm{t}_{\mathrm{i}}\right)+ \\
& \alpha \frac{\omega_{\mathrm{p}} / \mathrm{p}}{1+\omega_{\mathrm{p}}{ }^{2} / \mathrm{p}^{2}} \frac{\cos \left(\omega_{\mathrm{p}} \mathrm{t}+\psi\right)}{\sin \psi}
\end{aligned}
$$

For $\mathrm{t}=\mathrm{T}_{\mathrm{ex}}$ eqs. $(79 \mathrm{a}, \mathrm{b})$ become

$$
\begin{aligned}
& \theta\left(\mathrm{T}_{\mathrm{ex}}\right)=\mathrm{A}_{3} \sinh \mathrm{p}\left(\mathrm{T}_{\mathrm{ex}}-\mathrm{t}_{\mathrm{i}}\right)+\mathrm{A}_{4} \cosh \mathrm{p}\left(\mathrm{T}_{\mathrm{ex}}-\mathrm{t}_{\mathrm{i}}\right)+\alpha \\
& \frac{\dot{\theta}\left(\mathrm{T}_{\mathrm{ex}}\right)}{\mathrm{p}}=\mathrm{A}_{3} \cosh \mathrm{p}\left(\mathrm{T}_{\mathrm{ex}}-\mathrm{t}_{\mathrm{i}}\right)+\mathrm{A}_{4} \sinh \mathrm{p}\left(\mathrm{T}_{\mathrm{ex}}-\mathrm{t}_{\mathrm{i}}\right)+ \\
& \alpha \frac{\omega_{\mathrm{p}} / \mathrm{p}}{1+\omega_{\mathrm{p}}{ }^{2} / \mathrm{p}^{2}} \frac{1}{\sin \psi}
\end{aligned}
$$

where $A_{3}$ and $A_{4}$ are determined from the conditions occurring at the instant, $t=t_{i}$, which implies $\theta\left(t_{i}\right)=0$ and $\dot{\theta}^{\text {after }}\left(\mathrm{t}_{\mathrm{i}}\right)=\mathrm{e} \dot{\theta}^{\text {before }}\left(\mathrm{t}_{\mathrm{i}}\right)$, where $\quad \dot{\theta}^{\text {after }}\left(\mathrm{t}_{\mathrm{i}}\right)=\dot{\theta}_{+}, \quad \dot{\theta}^{\text {before }}\left(\mathrm{t}_{\mathrm{i}}\right)=\dot{\theta}_{-}$ and $\mathrm{e}$ is the coefficient of restitution. The last two initial conditions yield 
$\mathrm{A}_{4}=-\alpha-\frac{\alpha}{1+\omega_{\mathrm{p}}^{2} / \mathrm{p}^{2}} \frac{\sin \left(\omega_{\mathrm{p}} \mathrm{t}_{\mathrm{i}}+\psi\right)}{\sin \psi}$

and $\mathrm{A}_{3}=\frac{\mathrm{e} \dot{\theta}^{\text {before }}\left(\mathrm{t}_{\mathrm{i}}\right)}{\mathrm{p}}-\alpha \frac{\omega_{\mathrm{p}} / \mathrm{p}}{1+\omega_{\mathrm{p}}^{2} / \mathrm{p}^{2}} \frac{\cos \left(\omega_{\mathrm{p}} \mathrm{t}_{\mathrm{i}}+\psi\right)}{\sin \psi}$

Subsequently, the expressions $\theta\left(\mathrm{T}_{\mathrm{ex}}\right)-\alpha$ and $\dot{\theta}\left(\mathrm{T}_{\mathrm{ex}}\right) / \mathrm{p}$ taken from eqs. $(80 \mathrm{a}, \mathrm{b})$ are introduced into eq. (75) which lead to

$$
\left(\mathrm{A}_{3}+\mathrm{A}_{4}\right) \mathrm{e}^{\mathrm{p}\left(\mathrm{T}_{\mathrm{ex}}-\mathrm{t}_{\mathrm{i}}\right)}=-\alpha \frac{\omega_{\mathrm{p}} / \mathrm{p}}{1+\omega_{\mathrm{p}}^{2} / \mathrm{p}^{2}} \frac{1}{\sin \psi}
$$

where $A_{3}$ and $A_{4}$ are given in relations $(81 \& 82)$ as functions of $\dot{\theta}^{\text {before }}\left(\mathrm{t}_{\mathrm{i}}\right)$ and $\mathrm{t}_{\mathrm{i}}$ (impact time) both of which will be determined from the previous forced motion regime for $\mathrm{t} \leq \mathrm{t}_{\mathrm{i}}$ associated with eqs. (57a) and (59a) from which for $\theta(\mathrm{t})<0$ we obtain

$\theta\left(\mathrm{t}_{\mathrm{i}}\right)=\mathrm{A}_{1} \operatorname{sinhpt}_{\mathrm{i}}+\mathrm{A}_{2} \operatorname{coshpt}_{\mathrm{i}}-\alpha+\frac{\alpha}{1+\omega_{\mathrm{p}}{ }^{2} / \mathrm{p}^{2}} \frac{\sin \left(\omega_{\mathrm{p}} \mathrm{t}_{\mathrm{i}}+\psi\right)}{\sin \psi}$

$\frac{\dot{\theta}^{\text {before }}\left(\mathrm{t}_{\mathrm{i}}\right)}{\mathrm{p}}=\mathrm{A}_{1} \operatorname{coshpt} \mathrm{t}_{\mathrm{i}}+\mathrm{A}_{2} \operatorname{sinhpt} \mathrm{t}_{\mathrm{i}}+\frac{\alpha \omega_{\mathrm{p}} / \mathrm{p}}{1+\omega_{\mathrm{p}}{ }^{2} / \mathrm{p}^{2}} \frac{\cos \left(\omega_{\mathrm{p}} \mathrm{t}_{\mathrm{i}}+\psi\right)}{\sin \psi}$

where $A_{1}$ and $A_{2}$ are given in relation (70).

At the instant of impact, $\theta\left(\mathrm{t}_{\mathrm{i}}\right)=0$, which due to eq. (84) implies [4]

$$
\tan \psi=\frac{\sin \omega_{\mathrm{p}} \mathrm{t}_{\mathrm{i}}-\frac{\omega_{\mathrm{p}}}{\mathrm{p}} \operatorname{sinhpt}_{\mathrm{i}}}{1+\frac{\omega_{\mathrm{p}}^{2}}{\mathrm{p}^{2}}-\frac{\omega_{\mathrm{p}}^{2}}{\mathrm{p}^{2}} \operatorname{coshpt} \mathrm{t}_{\mathrm{i}}-\cos \omega_{\mathrm{p}} \mathrm{t}_{\mathrm{i}}} .
$$

Eq. (83) by virtue of relations (81) and (82) is written as follows

$$
\begin{aligned}
& \left(1+\frac{\omega_{\mathrm{p}}{ }^{2}}{\mathrm{p}^{2}}\right)\left[\frac{\mathrm{e} \dot{\theta}^{\text {before }}\left(\mathrm{t}_{\mathrm{i}}\right)}{\alpha \mathrm{p}}-1\right] \sin \psi-\frac{\omega_{\mathrm{p}}}{\mathrm{p}} \cos \left(\omega_{\mathrm{p}} \mathrm{t}_{\mathrm{i}}+\psi\right) \\
& -\sin \left(\omega_{\mathrm{p}} \mathrm{t}_{\mathrm{i}}+\psi\right)=-\frac{\omega_{\mathrm{p}}}{\mathrm{p}} \mathrm{e}^{-\mathrm{p}\left(\mathrm{T}_{\mathrm{ex}}-\mathrm{t}_{\mathrm{i}}\right)}
\end{aligned}
$$

From eq. (85) after substituting $\mathrm{A}_{1}$ and $\mathrm{A}_{2}$, taken from relation $(70)$, we obtain

$$
\frac{\dot{\theta}^{\text {before }}\left(\mathrm{t}_{\mathrm{i}}\right)}{\mathrm{p}}=\frac{\alpha \frac{\omega_{\mathrm{p}}}{\mathrm{p}}}{1+\frac{\omega_{\mathrm{p}}{ }^{2}}{\mathrm{p}^{2}}}\left(\frac{\cos \omega_{\mathrm{p}} \mathrm{t}_{\mathrm{i}}-\cosh \mathrm{pt}}{\tan \psi}+\frac{\omega_{\mathrm{p}}}{\mathrm{p}} \sinh \mathrm{pt} \mathrm{i}_{\mathrm{i}}-\sin \omega_{\mathrm{p}} \mathrm{t}_{\mathrm{i}}\right)
$$

Substituting the expression of $\dot{\theta}^{\text {before }}\left(\mathrm{t}_{\mathrm{i}}\right)$ from eq. (87b) into eq. (87a) we get

$$
\begin{aligned}
& \mathrm{e}\left(\operatorname{coshpt} \mathrm{t}_{\mathrm{i}}-\cos \omega_{\mathrm{p}} \mathrm{t}_{\mathrm{i}}\right) \cos \psi+ \\
& {\left[\mathrm{e}\left(\sin \omega_{\mathrm{p}} \mathrm{t}_{\mathrm{i}}-\frac{\omega_{\mathrm{p}}}{\mathrm{p}} \operatorname{sinhpt} \mathrm{t}_{\mathrm{i}}\right)+\frac{\mathrm{p}}{\omega_{\mathrm{p}}}+\frac{\omega_{\mathrm{p}}}{\mathrm{p}}\right] \sin \psi+} \\
& +\cos \left(\omega_{\mathrm{p}} \mathrm{t}+\psi\right)+\frac{\mathrm{p}}{\omega_{\mathrm{p}}} \sin \left(\omega_{\mathrm{p}} \mathrm{t}+\psi\right)=\mathrm{e}^{-\mathrm{p}\left(\mathrm{Tex}-\mathrm{t}_{\mathrm{i}}\right)} .
\end{aligned}
$$

Solving eqs. (86\&88) with respect to $\mathrm{t}_{\mathrm{i}}$ and $\psi$, we determine the minimum amplitude acceleration $\alpha_{\mathrm{p}} / \mathrm{g} \alpha=1 / \sin \psi$. As it will be shown numerically eqs. $(86 \& 88)$ yield acceptable solutions for $\mathrm{t}_{\mathrm{i}}<\mathrm{T}_{\mathrm{ex}}$ and $0<\omega_{\mathrm{p}} / \mathrm{p}<4.8$. For $\omega_{\mathrm{p}} / \mathrm{p}>4.8$ eqs. (86\&88) lead to physically unacceptable solutions corresponding to values of $t_{i}>T_{e x}$ which contradict the initial assumption $\left(\mathrm{t}_{\mathrm{i}}<\mathrm{T}_{\mathrm{ex}}\right)$ used for their derivation.

Case $2\left(t_{i}>T_{e x}\right)$

Impact will occur during the free-vibration regime at some time $\mathrm{t}=\mathrm{t}_{\mathrm{i}}$. Hence for $\mathrm{t}_{\mathrm{i}} \geq \mathrm{t} \geq(2 \pi-\psi) / \omega_{\mathrm{p}}$ due to eqs. $(65 \mathrm{a}, \mathrm{b})$ valid for $\theta(\mathrm{t})<0$ one can write the following equations

$$
\begin{gathered}
\theta(\mathrm{t})=\frac{\dot{\theta}\left(\mathrm{T}_{\mathrm{ex}}\right)}{\mathrm{p}} \sinh \mathrm{p}\left(\mathrm{t}-\mathrm{T}_{\mathrm{ex}}\right)+\left(\theta\left(\mathrm{T}_{\mathrm{ex}}\right)+\alpha\right) \cosh \mathrm{p}\left(\mathrm{t}-\mathrm{T}_{\mathrm{ex}}\right)-\alpha \\
\dot{\theta}^{\text {before }}(\mathrm{t}) / \mathrm{p}=\frac{\dot{\theta}\left(\mathrm{T}_{\mathrm{ex}}\right)}{\mathrm{p}} \cosh \mathrm{p}\left(\mathrm{t}-\mathrm{T}_{\mathrm{ex}}\right)+\left(\theta\left(\mathrm{T}_{\mathrm{ex}}\right)+\alpha\right) \sinh \mathrm{p}\left(\mathrm{t}-\mathrm{T}_{\mathrm{ex}}\right)
\end{gathered}
$$

where $\dot{\theta}\left(\mathrm{T}_{\mathrm{ex}}\right)$ and $\theta\left(\mathrm{T}_{\mathrm{ex}}\right)$ are evaluated form eqs. (57a) and (59a) at $\mathrm{t}=\mathrm{T}_{\mathrm{ex}}$. The resulting expressions after setting due to eq. (70)

$$
\mathrm{A}_{1}=-\frac{\alpha \omega_{\mathrm{p}} / \mathrm{p}}{1+\omega_{\mathrm{p}}^{2} / \mathrm{p}^{2}} \cot \psi, \mathrm{A}_{2}=\frac{\alpha \omega_{\mathrm{p}}^{2} / \mathrm{p}^{2}}{1+\omega_{\mathrm{p}}^{2} / \mathrm{p}^{2}}
$$

are given by

$$
\theta\left(\mathrm{T}_{\mathrm{ex}}\right)=-\frac{\alpha \omega_{\mathrm{p}} / \mathrm{p}}{1+\omega_{\mathrm{p}}{ }^{2} / \mathrm{p}^{2}} \cot \psi \sinh \mathrm{p} \mathrm{T}_{\mathrm{ex}}+\frac{\alpha \omega_{\mathrm{p}}^{2} / \mathrm{p}^{2}}{1+\omega_{\mathrm{p}}{ }^{2} / \mathrm{p}^{2}} \operatorname{coshp\mathrm {T}_{\mathrm {ex}}}-\alpha
$$

$\dot{\theta}\left(\mathrm{T}_{\mathrm{ex}}\right) / \mathrm{p}=-\frac{\alpha \omega_{\mathrm{p}} / \mathrm{p}}{1+\omega_{\mathrm{p}}{ }^{2} / \mathrm{p}^{2}} \cot \psi \cosh \mathrm{p} \mathrm{T}_{\mathrm{ex}}$

$+\frac{\alpha \omega_{\mathrm{p}}^{2} / \mathrm{p}^{2}}{1+\omega_{\mathrm{p}}^{2} / \mathrm{p}^{2}} \operatorname{sinhpT_{\mathrm {ex}}}+\frac{\alpha \omega_{\mathrm{p}} / \mathrm{p}}{1+\omega_{\mathrm{p}}^{2} / \mathrm{p}^{2}} \frac{1}{\sin \psi}$.

At the time of impact $t_{i}$, after taking into account that $\theta\left(t_{i}\right)=0$, eqs. $(89 a, b)$ by virtue of eqs. $(91 a, b)$ become

$$
\begin{aligned}
& \frac{\omega_{\mathrm{p}} / \mathrm{p}}{1+\omega_{\mathrm{p}}{ }^{2} / \mathrm{p}^{2}}\left[\left(\frac{\operatorname{coshp} \mathrm{T}_{\mathrm{ex}}}{\tan \psi}-\frac{\omega_{\mathrm{p}}}{\mathrm{p}} \operatorname{sinhp} \mathrm{T}_{\mathrm{ex}}-\frac{1}{\sin \psi}\right) \sinh \mathrm{p}\left(\mathrm{t}_{\mathrm{i}}-\mathrm{T}_{\mathrm{ex}}\right)+\right. \\
& \left.\left(\frac{\operatorname{sinhp} \mathrm{T}_{\mathrm{ex}}}{\tan \psi}-\frac{\omega_{\mathrm{p}}}{\mathrm{p}} \operatorname{coshp} \mathrm{T}_{\mathrm{ex}}\right) \operatorname{coshp}\left(\mathrm{t}_{\mathrm{i}}-\mathrm{T}_{\mathrm{ex}}\right)\right]=-1
\end{aligned}
$$

and 
$\dot{\theta}^{\text {before }}\left(\mathrm{t}_{\mathrm{i}}\right)=\frac{\alpha \omega_{\mathrm{p}}}{1+\omega_{\mathrm{p}}^{2} / \mathrm{p}^{2}}\left[\left(\frac{\omega_{\mathrm{p}}}{\mathrm{p}} \operatorname{sinhp} \mathrm{T}_{\mathrm{ex}}-\right.\right.$

$\left.-\frac{\operatorname{coshp} \mathrm{T}_{\mathrm{ex}}}{\tan \psi}+\frac{1}{\sin \psi}\right) \operatorname{coshp}\left(\mathrm{t}_{\mathrm{i}}-\mathrm{T}_{\mathrm{ex}}\right)+$

$\left.+\left(\frac{\omega_{\mathrm{p}}}{\mathrm{p}} \operatorname{coshp\mathrm {T}_{\mathrm {ex}}}-\frac{\operatorname{sinhp} \mathrm{T}_{\mathrm{ex}}}{\tan \psi}\right) \sinh \mathrm{p}\left(\mathrm{t}_{\mathrm{i}}-\mathrm{T}_{\mathrm{ex}}\right)\right]$

The governing equation after the impact (i.e. for $t \geq t_{i}$ where $\theta(\mathrm{t})>0)$ is

$\theta(t)=c_{1} \sinh p\left(t-t_{i}\right)+c_{2} \operatorname{coshp}\left(t-t_{i}\right)+\alpha$

and $\frac{\dot{\theta}(\mathrm{t})}{\mathrm{p}}=\mathrm{c}_{1} \cosh \mathrm{p}\left(\mathrm{t}-\mathrm{t}_{\mathrm{i}}\right)+\mathrm{c}_{2} \sinh \mathrm{p}\left(\mathrm{t}-\mathrm{t}_{\mathrm{i}}\right)$.

From the initial condition $\theta\left(\mathrm{t}_{\mathrm{i}}\right)=0$ we get $\mathrm{c}_{2}=-\alpha$, while $c_{1}=\dot{\theta}^{\text {atter }}\left(\mathrm{t}_{\mathrm{i}}\right) / \mathrm{p}=\mathrm{e} \dot{\theta}^{\text {before }}\left(\mathrm{t}_{\mathrm{i}}\right) / \mathrm{p}$. Introduction of the expressions of $c_{1}$ and $c_{2}$ into eqs. $(93 a, b)$ and application of the overturning conditions (60) at time $\mathrm{t}^{*}$ implying $\theta\left(\mathrm{t}^{*}\right)=\alpha$, $\dot{\theta}\left(\mathrm{t}^{*}\right)=0$, we obtain

$\frac{\dot{\theta}\left(\mathrm{t}_{\mathrm{i}}\right)}{\mathrm{p}} \sinh \mathrm{p}\left(\mathrm{t}^{*}-\mathrm{t}_{\mathrm{i}}\right)-\alpha \cosh \mathrm{p}\left(\mathrm{t}^{*}-\mathrm{t}_{\mathrm{i}}\right)=0$

$\frac{\dot{\theta}\left(\mathrm{t}_{\mathrm{i}}\right)}{\mathrm{p}} \cosh \mathrm{p}\left(\mathrm{t}^{*}-\mathrm{t}_{\mathrm{i}}\right)-\alpha \sinh \mathrm{p}\left(\mathrm{t}^{*}-\mathrm{t}_{\mathrm{i}}\right)=0$.

Elimination of $\sinh p\left(\mathrm{t}^{*}-\mathrm{t}_{\mathrm{i}}\right)$ and $\cosh \mathrm{p}\left(\mathrm{t}^{*}-\mathrm{t}_{\mathrm{i}}\right)$ yields

$\dot{\theta}^{\text {after }}\left(\mathrm{t}_{\mathrm{i}}\right)-\mathrm{p} \alpha=0$

and $\mathrm{e} \dot{\theta}^{\text {before }}\left(\mathrm{t}_{\mathrm{i}}\right)-\mathrm{p} \alpha=0$

where $\dot{\theta}^{\text {before }}\left(\mathrm{t}_{\mathrm{i}}\right)$ is taken from eq. $(92 \mathrm{~b})$.

Combining eqs. (92b) and (95) we obtain

$\frac{\mathrm{e} \omega_{\mathrm{p}} / \mathrm{p}}{1+\omega_{\mathrm{p}}^{2} / \mathrm{p}^{2}}\left[\left(\frac{\omega_{\mathrm{p}}}{\mathrm{p}} \sinh \mathrm{p} \mathrm{T}_{\mathrm{ex}}-\frac{\operatorname{coshp} \mathrm{T}_{\mathrm{ex}}}{\tan \psi}+\frac{1}{\sin \psi}\right) \cosh \mathrm{p}\left(\mathrm{t}_{\mathrm{i}}-\mathrm{T}_{\mathrm{ex}}\right)+\right.$

$\left.+\left(\frac{\omega_{p}}{p} \operatorname{coshp} T_{e x}-\frac{\sinh p T_{e x}}{\tan \psi}\right) \sinh p\left(t_{i}-T_{e x}\right)\right]=1$

Eqs. (92a) and (96) can be solved with respect to $\psi$ and $\mathrm{t}_{\mathrm{i}}$ leading to the minimum amplitude acceleration for overturning instability, i.e. $\alpha_{\mathrm{p}} / \alpha \mathrm{g}=1 / \sin \psi$. Note that although in the above four cases the dimensional amplitude $\alpha_{\mathrm{p}}$ depends on the angle $\alpha$, the corresponding curves $\alpha_{\mathrm{p}} / \alpha \mathrm{g}$ versus $\omega_{\mathrm{p}} / \mathrm{p}$ are independent of $\alpha$.

\section{The Effect of Initial Conditions (Fig. 2b)}

The occurrence of the case shown in Fig. (2b) will be discussed for a suddenly applied positive but decreasing ground acceleration, $\ddot{\mathrm{u}}_{\mathrm{g}}(\mathrm{t})$, in connection with the effect of initial (nontrivial) conditions $\theta(0)=\theta_{0} \neq 0, \dot{\theta}(0)=\dot{\theta}_{0} \neq 0$. For instance, one may assume the ground acceleration form $\ddot{\mathrm{u}}_{\mathrm{g}}(\mathrm{t})=\alpha_{\mathrm{p}} \sin \left(\omega_{\mathrm{p}} \mathrm{t}+\pi / 2+\psi\right)=\alpha_{\mathrm{p}} \cos \left(\omega_{\mathrm{p}} \mathrm{t}+\psi\right)$ which for $\mathrm{t}=0$ yields: $\quad \ddot{u}_{\mathrm{g}}(0)=\alpha_{\mathrm{p}} \cos \psi=\lambda \alpha_{\mathrm{p}}$ where $\psi=\cos ^{-1} \lambda, \alpha_{\mathrm{p}}=\mathrm{gtan} \alpha /$ $\cos \psi$ and $\alpha_{\mathrm{p}} / \mathrm{gtan} \alpha=1 / \cos \psi$. Then eq(56b) becomes:

$\ddot{\theta}-\mathrm{p}^{2} \theta=-\mathrm{p}^{2} \alpha-\mathrm{p}^{2} \alpha \frac{\cos \left(\omega_{\mathrm{p}} \mathrm{t}+\psi\right)}{\cos \psi}$

whose integral is

$\theta(t)=A_{3} \sinh p t+A_{4} \operatorname{coshpt}+\frac{\alpha}{1+\omega_{p}^{2} / p^{2}} \frac{\cos \left(\omega_{p} t+\psi\right)}{\cos \psi}+\alpha$

and $\frac{\dot{\theta}(\mathrm{t})}{\mathrm{p}}=\mathrm{A}_{3} \cosh \mathrm{pt}+\mathrm{A}_{4} \sinh \mathrm{pt}-\frac{\alpha \omega_{\mathrm{p}} / \mathrm{p}}{1+\omega_{\mathrm{p}}^{2} / \mathrm{p}^{2}} \frac{\sin \left(\omega_{\mathrm{p}} \mathrm{t}+\psi\right)}{\cos \psi}$

where

$\mathrm{A}_{3}=\frac{\dot{\theta}_{0}}{\mathrm{p}}+\alpha \frac{\omega_{\mathrm{p}} / \mathrm{p}}{1+\omega_{\mathrm{p}}^{2} / \mathrm{p}^{2}} \tan \psi, \mathrm{A}_{4}=\theta_{0}-\alpha \frac{2+\omega_{\mathrm{p}}^{2} / \mathrm{p}^{2}}{1+\omega_{\mathrm{p}}^{2} / \mathrm{p}^{2}}$

By virtue of eqs. (98\&99) and taking into account that $\mathrm{T}_{\mathrm{ex}}=(3 \pi / 2-\psi) / \omega_{\mathrm{p}}$ we obtain

$\theta\left(\mathrm{T}_{\mathrm{ex}}\right)=\mathrm{A}_{3} \operatorname{sinhp} \mathrm{T}_{\mathrm{ex}}+\mathrm{A}_{4} \operatorname{coshp\mathrm {T}_{\mathrm {ex}}}+\alpha$

and $\frac{\dot{\theta}\left(\mathrm{T}_{\mathrm{ex}}\right)}{\mathrm{p}}=\mathrm{A}_{3} \operatorname{coshp} \mathrm{T}_{\mathrm{ex}}+\mathrm{A}_{4} \sinh \mathrm{p} \mathrm{T}_{\mathrm{ex}}+\frac{\alpha \omega_{\mathrm{p}} / \mathrm{p}}{1+\omega_{\mathrm{p}}^{2} / \mathrm{p}^{2}} \frac{1}{\cos \psi}$

Introducing the above expressions of $\theta\left(\mathrm{T}_{\mathrm{ex}}\right)$ and $\dot{\theta}\left(\mathrm{T}_{\mathrm{ex}}\right)$ into the condition of overturning instability, eq. (75), we get

$\mathrm{A}_{3}+\mathrm{A}_{4}=-\frac{\alpha \omega_{\mathrm{p}} / \mathrm{p}}{1+\omega_{\mathrm{p}}^{2} / \mathrm{p}^{2}} \frac{1}{\cos \psi} \mathrm{e}^{-\mathrm{pT} \mathrm{T}_{\mathrm{ex}}}$

Eq. (102) using relations (100) yields

$\left[2 \frac{\mathrm{p}}{\omega_{\mathrm{p}}}+\frac{\omega_{\mathrm{p}}}{\mathrm{p}}-\frac{1}{\alpha}\left(\theta_{\mathrm{o}}+\frac{\dot{\theta}_{\mathrm{o}}}{\mathrm{p}}\right)\left(\frac{\mathrm{p}}{\omega_{\mathrm{p}}}+\frac{\omega_{\mathrm{p}}}{\mathrm{p}}\right)\right] \cos \psi-\sin \psi=\mathrm{e}^{-\mathrm{pT}_{\mathrm{ex}}}$

Eq. (103) can be solved with respect to $\psi$ as function of $\omega_{\mathrm{p}} / \mathrm{p}$ for given values of $\theta_{\mathrm{o}}$ and $\dot{\theta}_{\mathrm{o}}$.

For the sake of comparison of eq. (103) with eq. (71) the last one, in order to take into account non-trivial initial con$\operatorname{dition}\left(\theta_{\mathrm{o}} \neq 0\right.$ and $\left.\dot{\theta}_{\mathrm{o}} \neq 0\right)$, is written as follows

$\cos \psi-\left[\frac{\omega_{\mathrm{p}}}{\mathrm{p}}+\frac{1}{\alpha}\left(\theta_{\mathrm{o}}+\frac{\dot{\theta}_{\mathrm{o}}}{\mathrm{p}}\right)\left(\frac{\mathrm{p}}{\omega_{\mathrm{p}}}+\frac{\omega_{\mathrm{p}}}{\mathrm{p}}\right)\right] \sin \psi=\mathrm{e}^{-\mathrm{pT}_{\mathrm{ex}}}$

In case that $\theta_{0}$ and $\dot{\theta}_{\mathrm{o}}$ are negative eq. (104) leads to a lower curve in the versus $\omega_{\mathrm{p}} / \mathrm{p}$ (than that of trivial initial conditions) which represents the detrimental effect of negative initial conditions as is shown below.

\section{NUMERICAL RESULTS}

Numerical results are presented in both tabular and graphical form in time series and phase plane portraits [12]. Linearized dynamic solutions are compared with their corresponding non-linear solutions. First we consider mode 1 (no impact) based on eq.(71) for a one-sinus pulse (either posi- 
tive or negative). In this respect Figs. (8a and $\mathbf{8 b}$ ) show time series ( $\theta$ and $\dot{\theta}$ versus $\tau=\mathrm{pt}$, where $\tau$ is dimensionless time) for a block with $\mathrm{p}=2.14, \alpha=0.25$ and $\omega_{\mathrm{p}} / \mathrm{p}=2$. Fig. (8c) presents more clearly the conditions for overturning instability $(\theta=\alpha, \dot{\theta}=0)$ for the same block in terms of the phase-plane portrait. The continuous curve depicted in Figs. (8a to 8c) corresponds to $\alpha_{\mathrm{p}}=2.35766 \mathrm{~g} \alpha$ (no overturning), whereas the discontinuous curve corresponds to overturning instability with $\alpha_{p}=2.35771 \mathrm{~g} \alpha$. Similar results are shown in Figs. (9a) to $9 \mathrm{c}$ for this block when $\omega_{\mathrm{p}} / \mathrm{p}=4$. Apparently, the block returns to its initial equilibrium position for $\alpha_{\mathrm{p}}=5.3230 \mathrm{~g} \alpha$, while overturning instability occurs for $\alpha_{p}=5.32303 \mathrm{~g} \alpha$. Fig. (10) shows that the minimum amplitude acceleration for overturn-

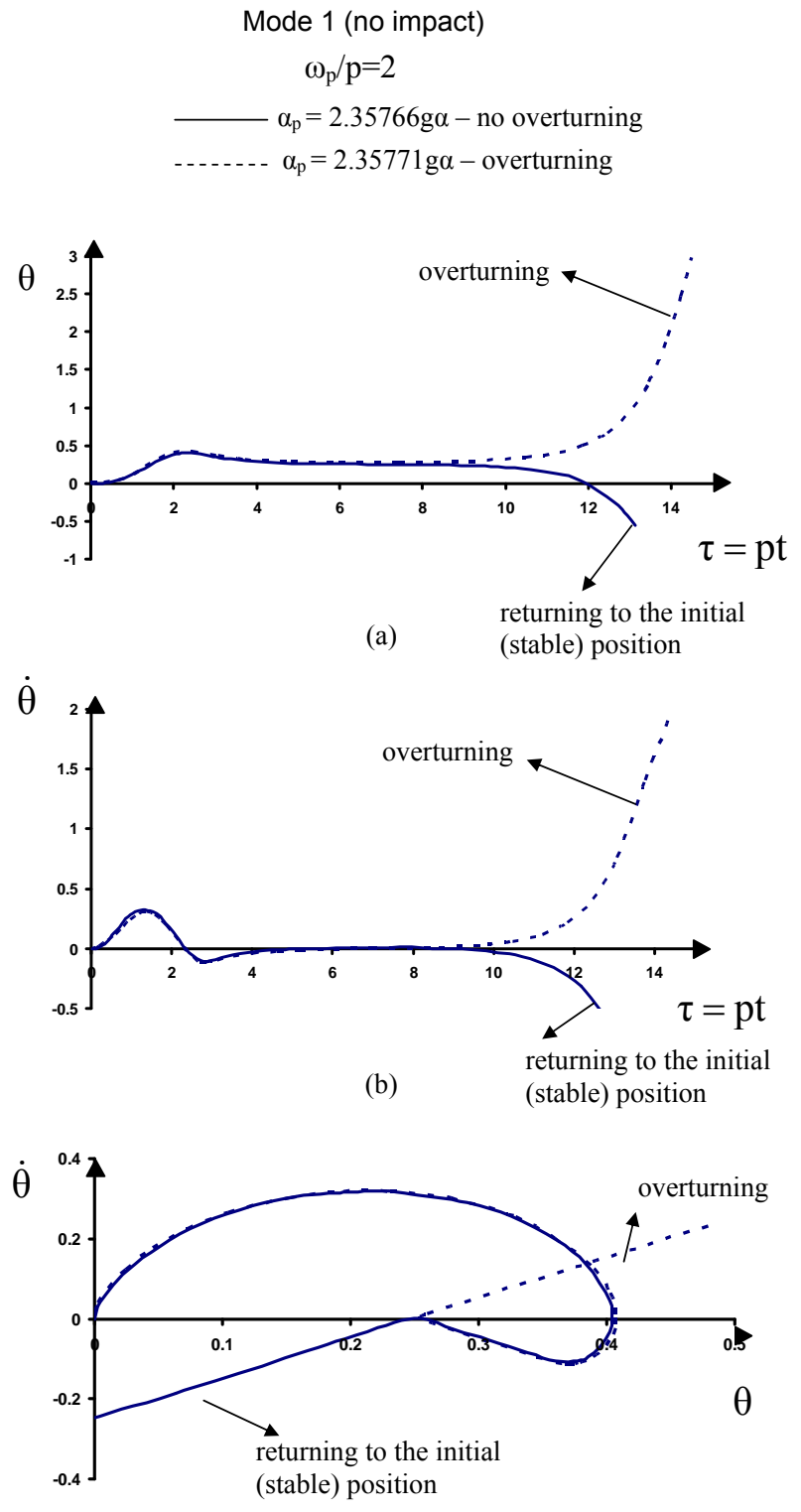

(c)

Fig. (8). Linearized solutions predicting the response of a rigid block (with $\mathrm{p}=2.14, \alpha=0.25$ and $\omega_{\mathrm{p}} / \mathrm{p}=2$ ) under one-sine pulse ground excitation presented as: (a) $\theta$ versus $\tau=\mathrm{pt}$, (b) $\dot{\theta}$ versus $\tau=\mathrm{pt}$ (where $\tau$ is dimensionless time) and (c) phase-plane portrait $\dot{\theta}$ versus $\theta$. ing instability for $0<\omega_{\mathrm{p}} / \mathrm{p}<10$ corresponds to mode 2 (one impact) associated with eqs $(86 \& 88)$ when $0<\omega_{\mathrm{p}} / \mathrm{p}<4.8$ and eqs $(92 \mathrm{a} \& 96)$ for $4.8<\omega_{\mathrm{p}} / \mathrm{p}<6.7$. Such a diagram coincides with that presented by Zhang and Makris (2001). Note that in Fig. (10) two physically unacceptable curves are also depicted based on eq. (78) (no impact) and eqs $(86 \& 88$ ) (one impact) which although analytically derived in earlier work [4] have not been presented in graphical form. Eq. (78) is physically unacceptable since - as explained in Section 3 yields $\theta(t)<0$ instead of $\theta(t)>0$ according to the case under discussion corresponding to Fig. (2b). Eqs(86\&88) (one impact) lead to the above unacceptable solutions presented in graphical form for $\left(t_{i}>T_{e x}\right)$ which contradict the initial assumption (i.e. $\mathrm{t}_{\mathrm{i}}<\mathrm{T}_{\mathrm{ex}}$ ).
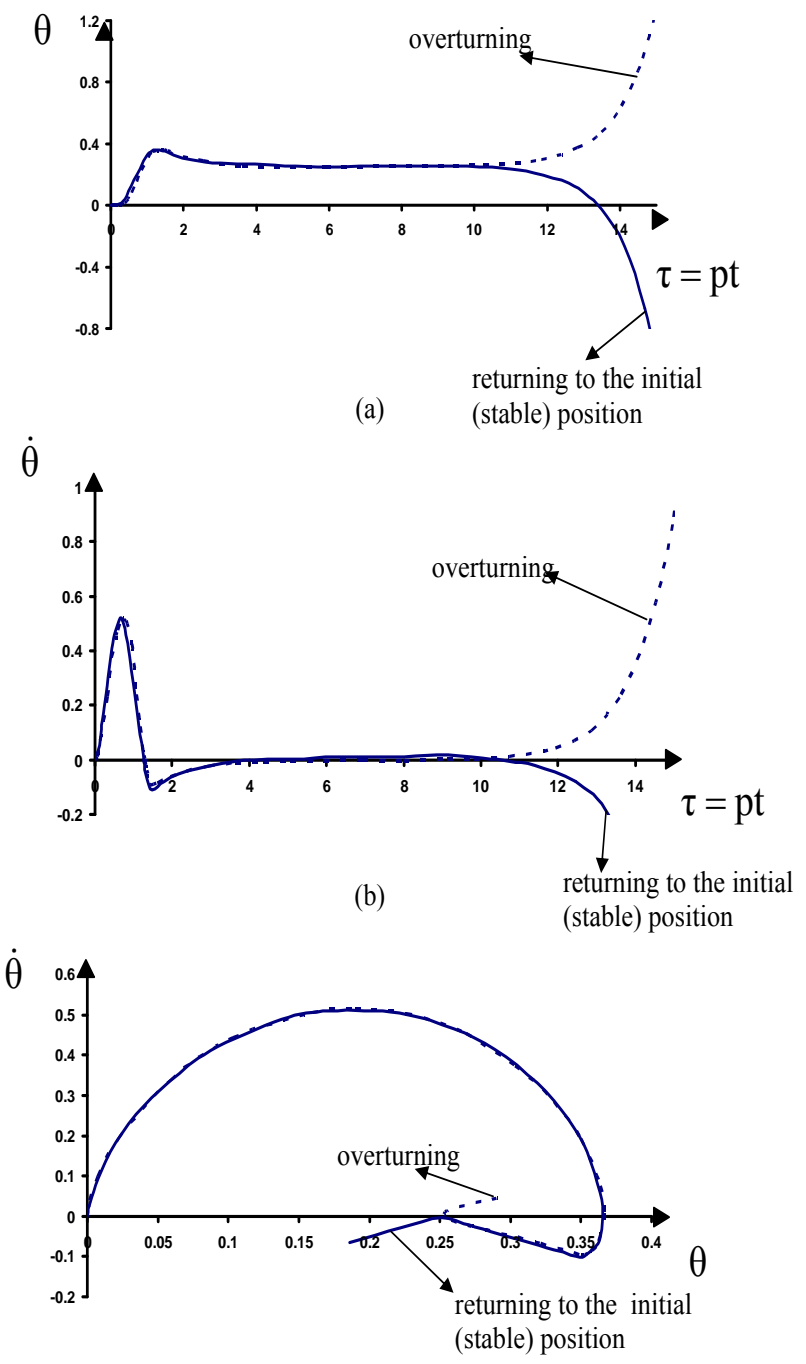

(c)

Fig. (9). Linearized solutions predicting the response of a rigid block (with $\mathrm{p}=2.14, \alpha=0.25$ and $\omega_{\mathrm{p}} / \mathrm{p}=4$ ) under one-sine pulse ground excitation presented as: (a) $\theta$ versus $\tau=\mathrm{pt}$, (b) $\dot{\theta}$ versus $\tau=\mathrm{pt}$ (where $\tau$ is dimensionless time) and (c) phase-plane portrait $\dot{\theta}$ versus $\theta$.

In Fig. (11) the linearized solutions of Fig. (10) (minimum $\alpha_{\mathrm{p}} / \mathrm{g} \alpha$ versus $\left.\omega_{\mathrm{p}} / \mathrm{p}\right)$ are compared with the nonlinear 


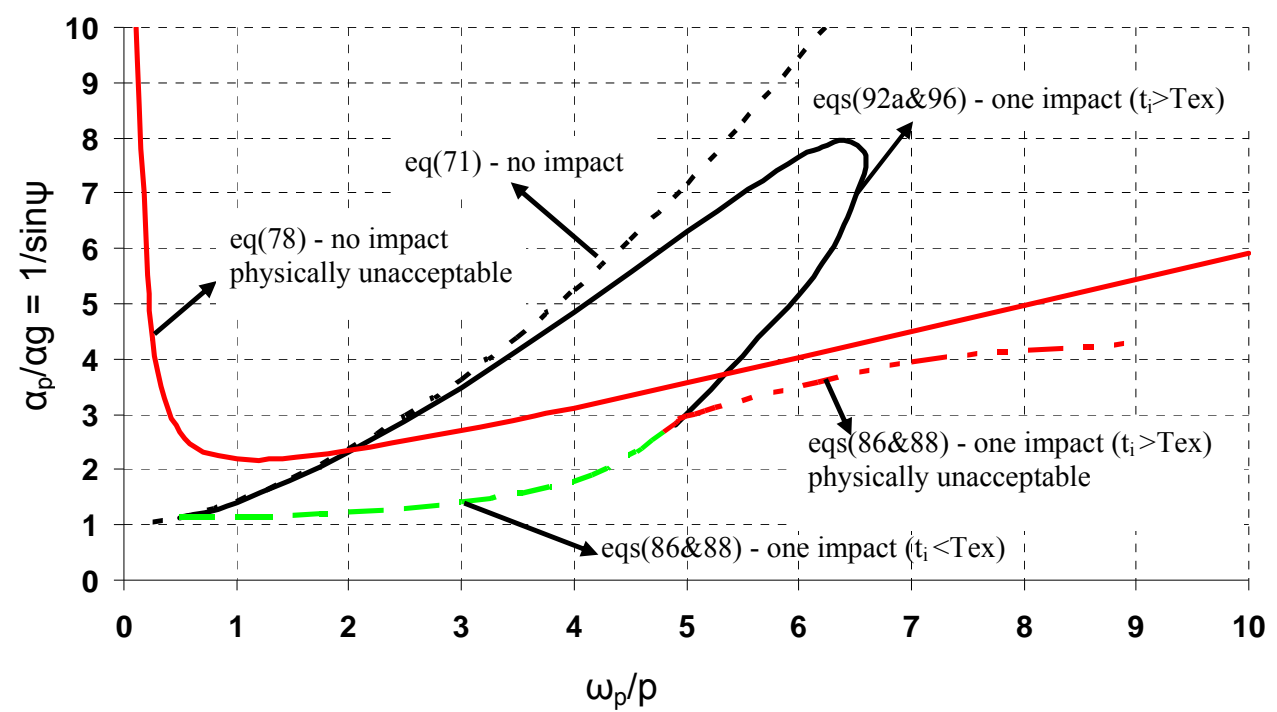

Fig. (10). The predicted values of minimum amplitude acceleration for overturning instability, $\alpha_{\mathrm{p}} / \alpha \mathrm{g}$ versus $\omega_{\mathrm{p}} / \mathrm{p}$.

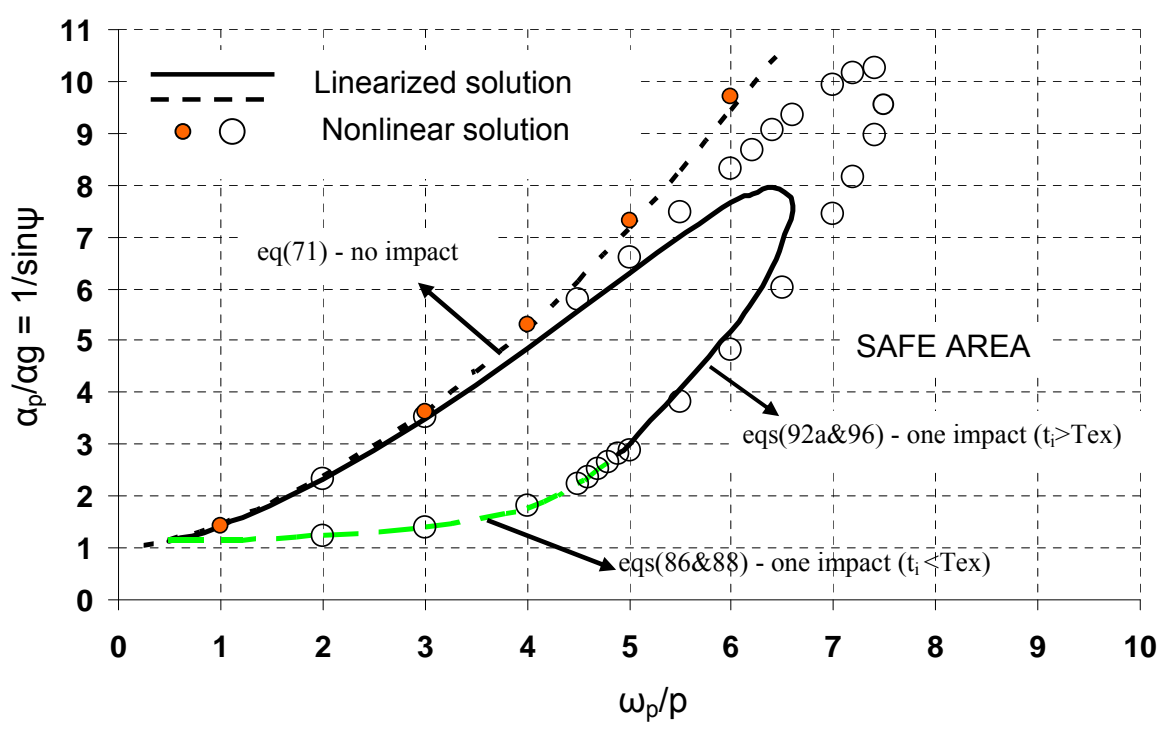

Fig. (11). Comparison of predicted values of minimum amplitude acceleration for overturning instability as obtained from the linearized solution and nonlinear analysis.

ones based on eqs. (21a,b) (solved numerically using Mathematica 6) being in good agreement.

Figs. (12a,b,c) show in terms of times series $(\theta(\tau)$ and $\dot{\theta}(\tau)$ versus $\tau)$ and phase-plane portrait $(\theta(\tau)$ versus $\dot{\theta}(\tau))$ the overturning instability corresponds to Mode 2 (one impact) for the same rigid block with $\omega_{\mathrm{p}} / \mathrm{p}=3 \quad[\mathrm{eqs}(86 \& 88)$, $\left.t_{i}<T_{e x}\right]$. Fig. (12c) illustrates the satisfaction of the overturning instability condition (i.e. $\theta=\alpha, \dot{\theta}=0$ ). Note that the minimum amplitude acceleration leading to overturning instability is $\alpha_{\mathrm{p}} / \alpha \mathrm{g}=0.71157$, while for $\alpha_{\mathrm{p}} / \alpha \mathrm{g}=0.71156$ the block does not overturn but returns to its initial stable equilibrium position. Similar predictions to those presented in Fig. (12) are presented in Fig. (13) for the same rigid block but for $\omega_{\mathrm{p}} / \mathrm{p}=5.5$ [eqs. $(92 \mathrm{a} \& 96), \mathrm{t}_{\mathrm{i}}>\mathrm{T}_{\mathrm{ex}}$ ].
Overturning instability associated with the response shown in Fig. (2b) is not possible to occur in the case of a suddenly applied positive (either increasing or decreasing) one-sinus or one-cosinus pulse in connection with trivial initial conditions. However, such a type of overturning instability may occur in cases of non-trivial initial conditions $\left(\theta_{\mathrm{o}}=0.01, \dot{\theta}_{\mathrm{o}} \leq 0.2\right)$ in connection with a suddenly applied positive but decreasing one-cosine pulse. Thus, one may assume a small initial imperfection $\theta_{0}<0.01 \mathrm{rad}$ and a small initial angular velocity $\dot{\theta}_{\mathrm{o}} \leq 0.2 \mathrm{rad} / \mathrm{sec}$. Fig. (14) provides the minimum amplitude acceleration $\left(\alpha_{\mathrm{p}} / \alpha \mathrm{g}=1 / \cos \psi\right.$ versus $\omega_{\mathrm{p}} / \mathrm{p}$ ) corresponding to Fig. (2b) for the case of a ground acceleration $\ddot{\mathrm{u}}_{\mathrm{g}}(\mathrm{t})=\alpha_{\mathrm{p}} \cos \left(\omega_{\mathrm{p}} \mathrm{t}+\psi\right)$. In such a case (Mode 
1 , no impact) eq. (103) is more unfavorable compared to the predictions of eq. (71) and eq. (104) associated with $\ddot{u}_{\mathrm{g}}(\mathrm{t})=\alpha_{\mathrm{p}} \sin \left(\omega_{\mathrm{p}} \mathrm{t}+\psi\right)$.

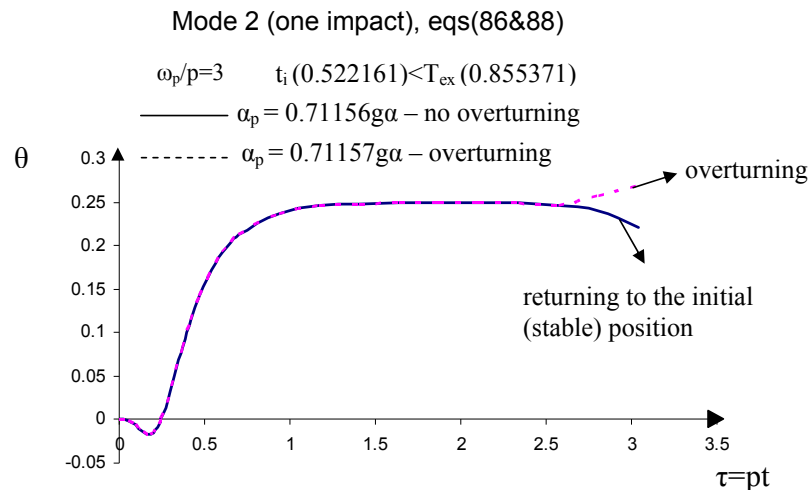

(a)

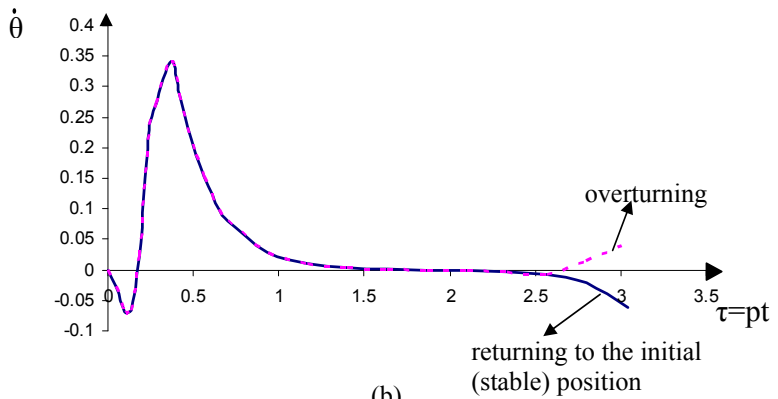

(b)

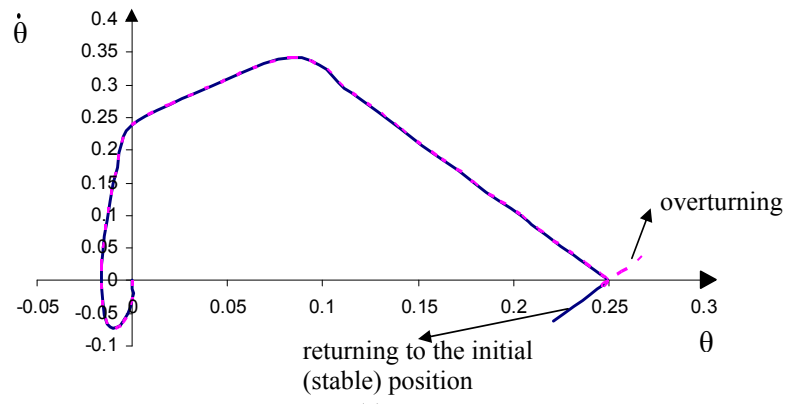

(c)

Fig. (12). Linearized solutions predicting the response of a rigid block (with $\mathrm{p}=2.14, \alpha=0.25$ and $\omega_{\mathrm{p}} / \mathrm{p}=3$ ) under one-sine pulse ground excitation presented as: (a) $\theta$ versus $\tau=\mathrm{pt}$, (b) $\dot{\theta}$ versus $\tau=\mathrm{pt}$ (where $\tau$ is dimensionless time) and (c) phase-plane portrait $\dot{\theta}$ versus $\theta$.

From all the above numerical results the most unfavorable (smallest) minimum amplitude ground acceleration (corresponding to $\omega_{\mathrm{p}} / \mathrm{p}=1$ ) is equal to $\alpha_{\mathrm{p}}=\alpha \mathrm{g}$ and (since $1 / \sin \psi=1$ ) hence for $\alpha=0.25, \alpha_{p}=0.25 \mathrm{~g}$. This corresponds to a period of ground acceleration $\mathrm{T}_{\mathrm{ex}}=\mathrm{T}=(2 \pi-\psi) / \omega_{\mathrm{p}}=2.201 \mathrm{sec}$. For $\omega_{\mathrm{p}} / \mathrm{p}=4$ we get $\alpha_{\mathrm{p}}=2 \alpha \mathrm{g}=0.5 \mathrm{~g}$ with corresponding period $\mathrm{T}=(2 \pi-\psi) / \omega_{\mathrm{p}}=0.672 \mathrm{sec}$. Both cases indicate in general safety against earthquake according to typical acceleration response spectra. The various curves shown in Fig. (14) can also be presented in terms of $\alpha_{\mathrm{p}} / \mathrm{g}$ versus the period of forcing excita-

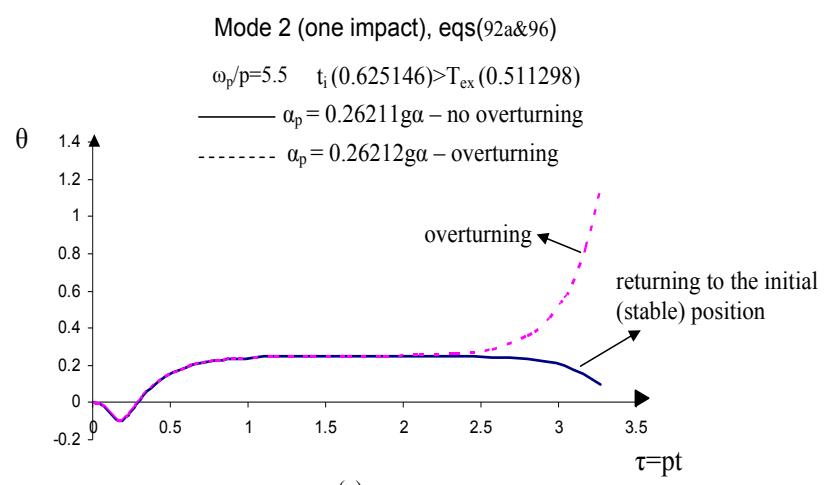

(a)

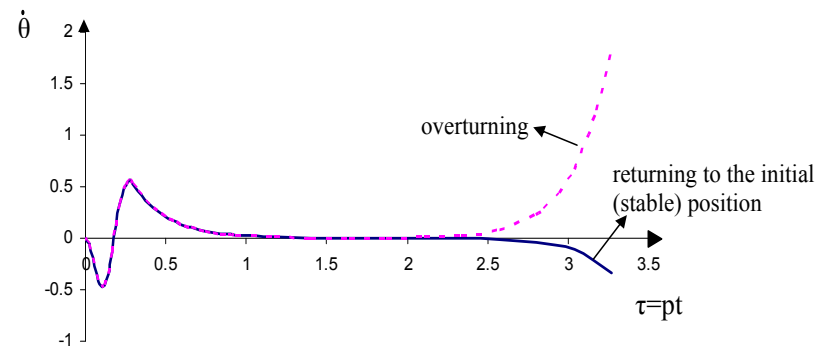

(b)

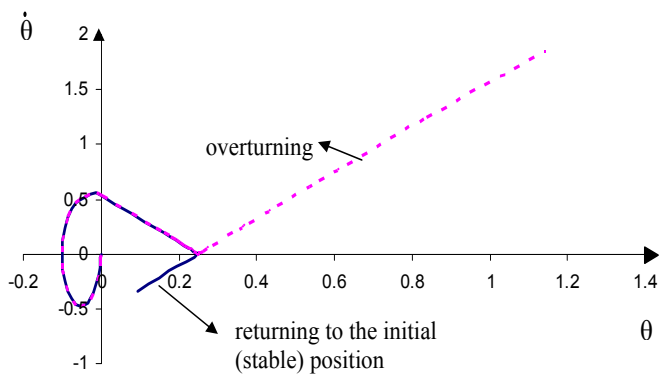

(c)

Fig. (13). Linearized solutions predicting the response of a rigid block with $\mathrm{p}=2.14, \alpha=0.25$ and $\omega_{\mathrm{p}} / \mathrm{p}=5.5$ ) under one-sine pulse ground excitation presented as: (a) $\theta$ versus $\tau=\mathrm{pt}$, (b) $\dot{\theta}$ versus $\tau=\mathrm{pt}$ (where $\tau$ is dimensionless time) and (c) phase-plane portrait $\dot{\theta}$ versus $\theta$.

tion, $\mathrm{T}_{\mathrm{ex}}=\mathrm{T}$. The corresponding curves $\alpha_{\mathrm{p}} / \mathrm{g}$ versus $\mathrm{T}$ are shown in Fig. (15). In order to investigate whether the maximum amplitude of ground acceleration are safe against regional earthquake hazard we will compare the lower curves of Fig. (15) with those of standard design codes for two types of soil foundation, type and A (rock or other rock-like geological formation) and $\mathrm{B}$ (deposits of very dense sand, gravel, or very stiff clay). From Figs. $(\mathbf{1 6} \mathbf{a}, \mathbf{b})$ one can see that depicted values of minimum amplitude acceleration are higher than the corresponding values obtained from the response spectra of EC8 for soil foundation Type A and both cases of damping, $\xi=3 \%$ and $\xi=5 \%$. 


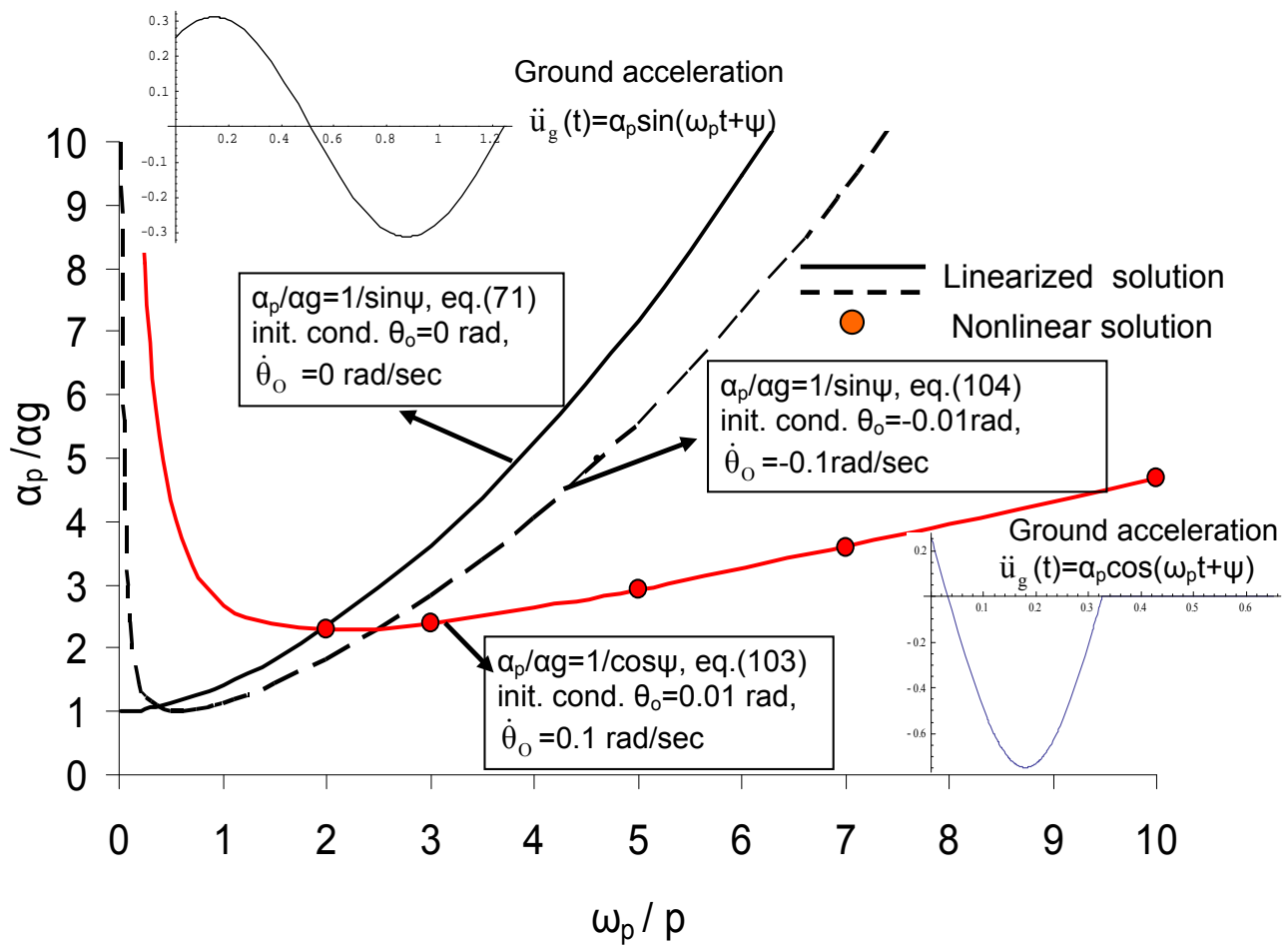

Fig. (14). The predicted values of minimum amplitude acceleration for overturning instability, $\alpha_{\mathrm{p}} / \alpha \mathrm{g}$ versus $\omega_{\mathrm{p}} / \mathrm{p}$, for the trivial initial conditions $\theta_{0}=\dot{\theta}_{\mathrm{o}}=0$ and the nontrivial ones: $\theta_{\mathrm{o}}= \pm 0.01 \mathrm{rad}, \pm \dot{\theta}_{\mathrm{o}}=0.1 \mathrm{rad} / \mathrm{sec}$.

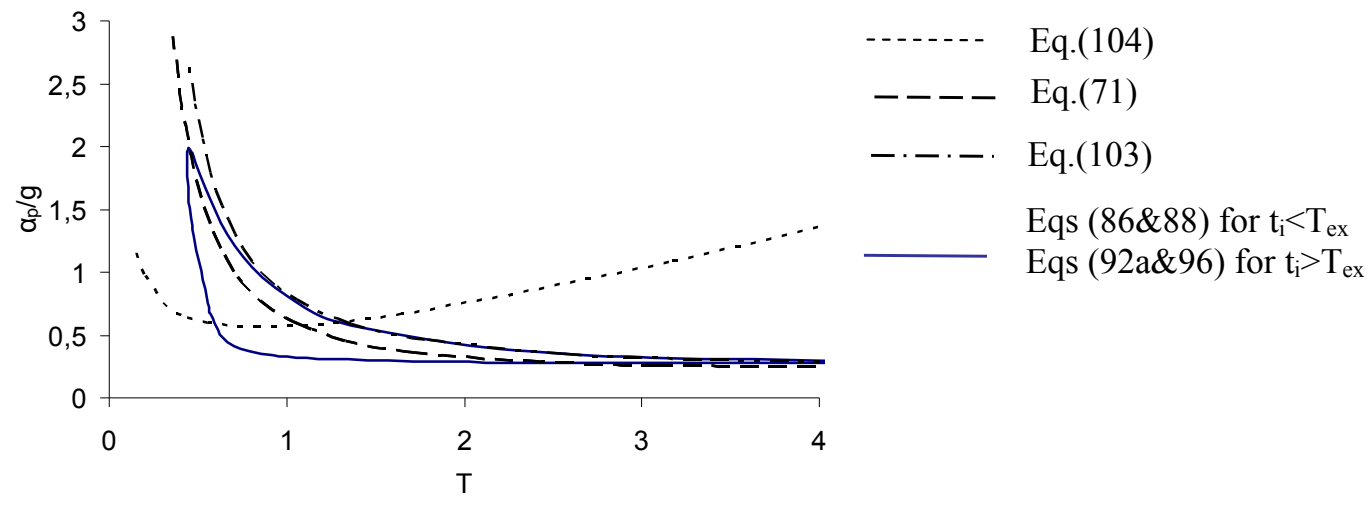

Fig. (15). Curves of minimum amplitude ground acceleration $\alpha_{\mathrm{p}} / \mathrm{g}$ versus $\mathrm{T}$ (period of forcing function).

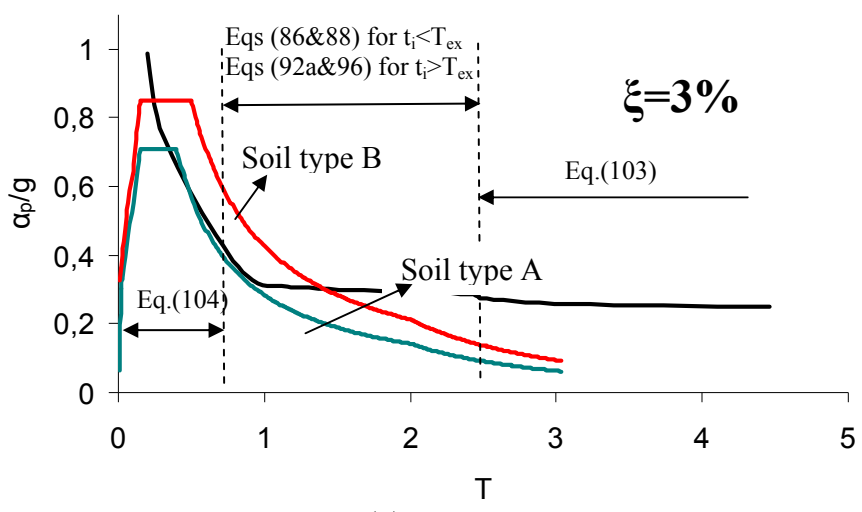

(a)

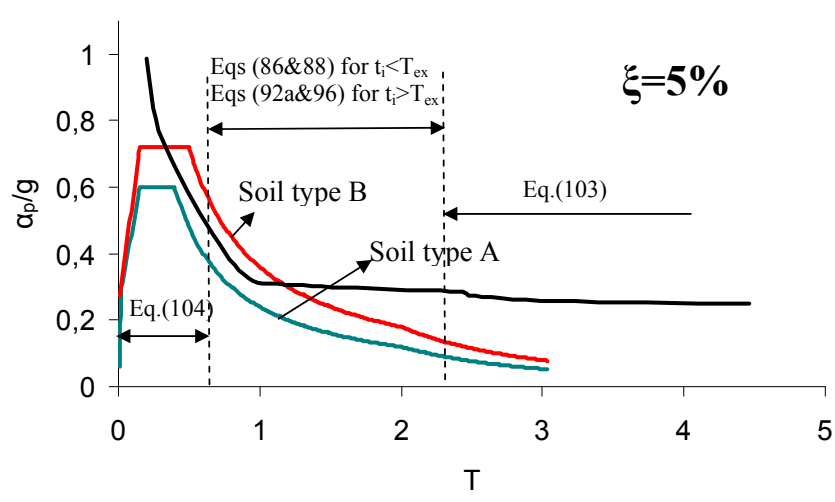

(b)

Fig. (16). Comparison of minimum amplitude acceleration $\alpha_{\mathrm{p}} / \mathrm{g}$ versus $\mathrm{T}$ (period of forcing function) with the corresponding predictions of EC8 for two types of soil foundation (A and B) and damping: (a) $\xi=3 \%$ and (b) $\xi=5 \%$. 


\section{CONCLUSIONS}

In this study dealing with the overturning instability of a free-standing rigid block under ground excitation and assuming that there is no sliding due to large friction, the following conclusions are worth mentioning:

1. The governing equations of rocking motion of the rigid block are comprehensively derived using energy considerations.

2. The condition of overturning instability occurring via the unstable equilibrium of the block is properly established by considering that such a critical state is related to the minimum amplitude ground acceleration. If this is so, one can assume that the block oscillates for a short time about the unstable equilibrium implying, thus, zero angular velocity.

3. A detailed linearized analysis under a one-sine pulse ground excitation either without impact or with one impact (occurring either before or after the ground acceleration expires) facilitates to understand the mechanism of such a type of instability. The comparison of the above results with those obtained by nonlinear dynamic analyses shows the regions of agreement and disagreement between linearized and nonlinear analyses.

4. New interesting, for structural design purposes, analytical and graphical results yielding the minimum amplitude ground acceleration are assessed covering various cases of overturning instability under a onesine pulse. According to these results the safe area in the diagram $\alpha_{\mathrm{p}} / \mathrm{g} \alpha$ versus $\omega_{\mathrm{p}} / \mathrm{p}$ for the case shown in Fig. (2a) [either with mode 1 (no impact) or with mode 2 (one impact)] coincides with that presented in previous work [6]. The solution for overturning instability according to Fig. (2b) is physically unacceptable for a suddenly applied positive acceleration either of one-sine or one-cosine pulse. However, such a type of overturning instability may occur in case of non trivial initial conditions under a suddenly applied positive but decreasing one-cosine pulse.

5. Time series and mainly phase-plane portraits illustrate the rocking response and the subsequent overturning instability criterion of the block.

6. The effect of initial conditions on the minimum amplitude of ground acceleration in connection with a one-cosine pulse is discussed. Such a case may lead the block to overturning instability according to Fig. (2b).

7. The detrimental effect of initial conditions on the minimum amplitude acceleration in connection with a one-sine pulse is also assessed.
8. From a comparison of the last two cases one can conclude that the one cosine pulse leads to much more unfavorable results than those of the one-sinus pulse.

9. From all the above numerical results, the most unfavorable regarding the minimum amplitude ground acceleration indicate safety against earthquakes according to the predictions of the response spectra of Standard EC8 for both damping cases $\xi=3 \%$ and $5 \%$ for type A of soil foundation. However, this magnitude of $\alpha_{p}$ should be substantially reduced if the rigid block were supported on the top surface of a multi-drum column yielding loss of energy due to sliding and impact between drums. This implies seismic protection excluding overturning instability for the above types of ground excitation and both types of soil foundation and damping.

\section{ACKNOWLEDGEMENT}

The author is indebted to Dr. D.M. Cotsovos for the computation of the numerical results and their presentation in graphical form.

\section{REFERENCES}

[1] Shenton HW. Criteria for initiation of slide, rock, and slide-rock rigid-body modes. J Eng Mech ASCE 1996; 122(7): 690-3.

[2] Pompei A, Scalia A, Sumbatyan MA. Dynamics of rigid block due to horizontal ground motion. J Eng Mech 1998; 124 (7): 713-7.

[3] Makris N, Roussos YS. Rocking response of rigid blocks under near-source ground motions. Geotechnique 2000; 50: 243-62.

[4] Zhang J, Makris N. Rocking response of free-standing blocks under cycloid pulses. J Eng Mech 2001; 127: 473-83.

[5] Makris N, Konstantinidis D. The rocking spectrum and the limitations of practical design methodologies. Earthquake Eng Struct Dyn 2003; 32(12): 265-89.

[6] Konstantinidis D, Makris N. Seismic response analysis of multidrum classical columns. Earthquake Eng Struct Dyn 2005; (submitted for publication).

[7] Kounadis AN. Dynamics of continuous elastic systems. $2^{\text {nd }}$ ed. NTUA: Athens, 1989.

[8] Kounadis AN. Nonlinear theory of elastic stability with elements of catastrophy theory. Athens: Simeon 1998.

[9] Kounadis AN, Makris N. Restoration-preservation and seismic stability of the statues of athena and apollo on the forefront of the academy of athens. (Submitted in Special issue of SpringerVerlag).

[10] Housner GW. The behavior of inverted pendulum structure during earthquakes. Bull Seismol Soc Am 1963; 53(2): 403-17.

[11] Konstantinidis D, Makris N. Experimental and analytical studies on the seismic response of free-standing and anchored laboratory equipment. Pacific earthquake engineering research centre, College of Engineering, University of California, Berkeley Report No. PEER 2005/07, January 2005.

[12] Kounadis AN. Flutter and other singularity phenomena in symmetric systems via combination of mass distribution and weak damping. Int J Nonlinear Mech 2007; 42: 24-35. 